\title{
Orthogonal Regulatory Circuits for Escherichia coli Based on the gamma-Butyrolactone System of Streptomyces coelicolor
}

DOI:

10.1021/acssynbio.7b00425

\section{Document Version}

Accepted author manuscript

Link to publication record in Manchester Research Explorer

Citation for published version (APA):

Biarnes-Carrera, M., Lee, C. K., Nihira, T., Breitling, R., \& Takano, E. (2018). Orthogonal Regulatory Circuits for Escherichia coli Based on the gamma-Butyrolactone System of Streptomyces coelicolor. ACS Synthetic Biology, 7(4), 1043-1055. https://doi.org/10.1021/acssynbio.7b00425

\section{Published in:}

ACS Synthetic Biology

\section{Citing this paper}

Please note that where the full-text provided on Manchester Research Explorer is the Author Accepted Manuscript or Proof version this may differ from the final Published version. If citing, it is advised that you check and use the publisher's definitive version.

\section{General rights}

Copyright and moral rights for the publications made accessible in the Research Explorer are retained by the authors and/or other copyright owners and it is a condition of accessing publications that users recognise and abide by the legal requirements associated with these rights.

\section{Takedown policy}

If you believe that this document breaches copyright please refer to the University of Manchester's Takedown Procedures [http://man.ac.uk/04Y6Bo] or contact uml.scholarlycommunications@manchester.ac.uk providing relevant details, so we can investigate your claim.

\section{OPEN ACCESS}


1 Orthogonal regulatory circuits for $E$. coli based on the $\boldsymbol{\gamma}$-butyrolactone

2 system of Streptomyces coelicolor

3 Author list: Marc Biarnes-Carrera ${ }^{1}$, Chang-Kwon Lee ${ }^{2,4}$, Takuya Nihira ${ }^{2,3}$, Rainer Breitling ${ }^{1}$

4 and Eriko Takano ${ }^{1}$

5 Affiliation:

$6{ }^{1}$ Manchester Centre for Synthetic Biology of Fine and Speciality Chemicals 7 (SYNBIOCHEM), Manchester Institute of Biotechnology, School of Chemistry, Faculty of

8 Science and Engineering, University of Manchester, 131 Princess Street, Manchester M1

9 7DN, United Kingdom.

10 International Center for Biotechnology, Osaka University, 2-1 Yamadaoka, Suita, Osaka 11 565-0871, Japan

$12{ }^{3}$ Mahidol University-Osaka University Collaborative Research Center for Bioscience and 13 Biotechnology, Faculty of Science, Mahidol University, Rama VI Rd., Bangkok 10400, 14 Thailand

$15{ }^{4}$ Present address: Mong-Go Food Co., Ltd., Changwon 641-847, Republic of Korea

16 Corresponding author: Eriko Takano, eriko.takano@manchester.ac.uk

17 Graphical Abstract

18
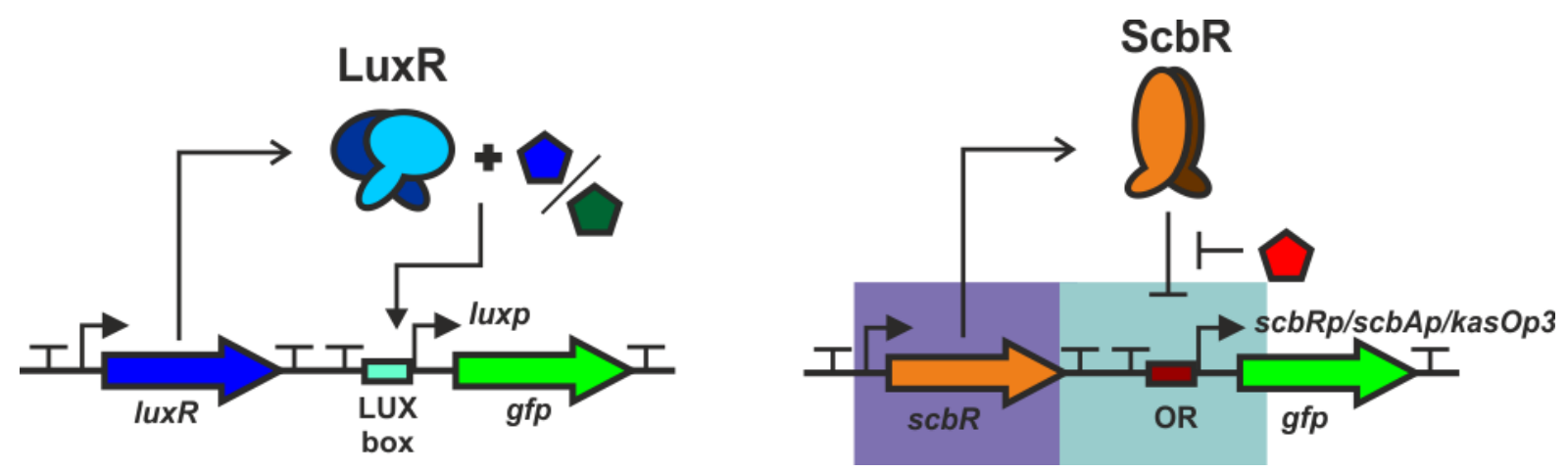

\section{Abstract}

20 Chemically inducible transcription factors are widely used to control gene expression of 21 synthetic devices. The bacterial quorum sensing system is a popular tool to achieve such 22 control. However, different quorum sensing systems have been found to cross-talk, both 
23 between themselves and with the hosts of these devices, and they are leaky by nature. Here 24 we evaluate the potential use of the $\gamma$-butyrolactone system from Streptomyces coelicolor A3(2) M145 as a complementary regulatory circuit. First, two additional genes responsible for the biosynthesis of $\gamma$-butyrolactones were identified in S. coelicolor M145 and then expressed in E. coli BL21 under various experimental conditions. Second, the $\gamma$ butyrolactone receptor ScbR was optimised for expression in E. coli BL21. Finally, signal and promoter crosstalk between the $\gamma$-butyrolactone system from $S$. coelicolor and quorum sensing systems from Vibrio fischeri and Pseudomonas aeruginosa was evaluated. The results show that the $\gamma$-butyrolactone system does not crosstalk with the quorum sensing systems and can be used to generate orthogonal synthetic circuits.

\section{Keywords}

$34 \gamma$-butyrolactone; Streptomyces; synthetic biology; orthogonal regulatory circuit; quorum sensing

Synthetic biology aims at the rational design of living organisms with novel functionalities ${ }^{1}$.

One major challenge is to develop new regulatory circuits that allow for tight regulation over a wide variety of conditions ${ }^{2,3}$. Various tools are available to control transcript levels ${ }^{4,5}$, translation rates ${ }^{6}$ or protein concentration ${ }^{7,8}$. One popular tool is the use of chemicallyinducible transcription factors to regulate the expression of genes of interest ${ }^{3,9}$, such as the acyl-homoserine lactones (AHL) from the bacterial quorum sensing (QS) system 3,10, originally derived from the microorganism Vibrio fischerii ${ }^{11}$. This system has been previously used to generate devices such as oscillators ${ }^{12}$ or logic gates ${ }^{13}$ and is currently being seen as a promising tool to engineer microbial consortia ${ }^{10}$, mainly due to the large diversity of well-characterised AHL systems reported. However, despite these promising applications and perspectives, different AHL devices have been found to cross-talk ${ }^{14}$, either at the promoter or the signal level ${ }^{10}$; a limitation that can result in undesirable or unpredictable outcomes. Furthermore, some AHL systems control the expression of virulence

50 factors, such as the one from Pseudomonas aeruginosa ${ }^{15}$, and consequently organisms have evolved to target these molecules using so-called quorum quenchers ${ }^{16}$, which function as either lactonases or acylases. This can limit the application of QS systems in some hosts, such 
54 signal in the AHL-based synthetic circuits, is leaky ${ }^{19}$, resulting in sometimes undesired high 55 basal expression of the output signal.

56 Members of the genus Streptomyces have been widely researched due to their ability to 57 produce a vast array of secondary metabolites, many of which have medical interest ${ }^{20}$. In 58 Streptomyces, cell-to-cell communication is crucial to coordinate the onset of antibiotic 59 production, as the final compound would be toxic to cells that have not developed the 60 corresponding resistance. This coordination is achieved through the use of small diffusible 61 molecules known as $\gamma$-butyrolactones (GBLs) ${ }^{21}$. These bacterial hormones are species62 specific ${ }^{22}$, and although some recent publications ${ }^{23,24}$ have shown that different 63 Streptomyces species can share a common GBL, currently there is no evidence of signal 64 cross-talk between different GBL regulators at physiological concentrations ${ }^{25}$. In 65 Streptomyces, GBLs promote a growth phase-dependent switch-like transition to antibiotic 66 production by binding to their cognate receptor protein, a homodimer from the TetR family 67 of repressors. These repressors are the master regulators of biosynthetic gene clusters and in 68 some instances ${ }^{26-28}$ they also regulate their own transcription and that of a GBL synthase 69 protein.

70 In this study, we evaluated the potential application of the GBL system from S. coelicolor as 71 a regulatory tool for synthetic biology in E. coli. We show that this system can be used as a 72 versatile and accessible tool to activate gene circuits in the heterologous host, with minimal 73 crosstalk with the QS systems from $V$. fischeri and $P$. aeruginosa, and that it allows for tight 74 control of genes of interest. To achieve this, we have generated a plasmid for production of 75 GBL SCB2 in E. coli and a series of plasmids constitutively expressing an optimised version 76 of ScbR and a library of Streptomyces-derived promoters: $s c b R p$, $s c b A p$ or $c p k O p$, that are 77 controlling the expression of $g f p$. 
a) The SCO6264 and SCO6267 genes from S. coelicolor are essential for GBL production

81

82

83

84

85

86

87

88

89

90

In Streptomyces, the biosynthesis of GBLs is reported to start with a condensation between dihydroxyacetone phosphate (DHAP) and a $\beta$-ketoacyl-acyl carrier protein (ACP) ${ }^{29}$, followed by an intramolecular aldol condensation that yields the corresponding butenolide (Fig. 1, compound 4). In S. coelicolor, the enzyme responsible for this catalytic step is known as ScbA ${ }^{26,32}$. Previous in vitro studies with homologues from Streptomyces griseus ${ }^{29}$ and Streptomyces virginiae ${ }^{30}$ showed that after this first condensation, the butenolide is enzymatically reduced in an NADPH-dependent manner to generate the reduced GBL (compound 5). In some Streptomyces species, this compound undergoes a second enzymatic NADPH-dependent reduction that stereo-specifically reduces the carbonyl in $\mathrm{C}_{6}$ into an (R)or (S)-alcohol ${ }^{30}$ (compound 7). However, to our knowledge, no homologues of these enzymes have been identified and characterised in S. coelicolor. Using a BLASTp search we identified SCO6264 (herafter $s c b B, 31 \%$ amino acid identity to BarS1 ${ }^{30}$ ) as a putative 3ketoacyl-ACP/Coenzyme A (CoA) reductase from the short-chain alcohol dehydrogenase superfamily and SCO6267 (hereafter scbC, $76 \%$ amino acid identity to BprA ${ }^{29}$ and $45 \%$ amino acid identity to BarS2 ${ }^{33}$ ) as a putative butenolide phosphate reductase.

To confirm the involvement of ScbB and ScbC in GBL biosynthesis, insertion mutants of $s c b B$ and scbC, LW107 and LW108, respectively, were generated in S. coelicolor M145. The mutant strains were grown in SFM solid medium, their GBLs extracted and analysed using the kanamycin bioassay ${ }^{34}$ (Fig. 2). In this assay, only spiking of ethyl acetate extracts resuspended in methanol from strains that produce GBLs will be able to allow growth of reporter strain LW94 in a kanamycin-supplemented medium.

Production of GBLs was detected in the wild-type S. coelicolor M145 at all tested extract volumes, using the kanamycin bioassay. However, the indicator strain failed to grow in presence of either LW107 $(s c b A / C)$ or LW108 ( $s c b A / B)$ extracts, suggesting that these mutants are not able to produce the GBLs, confirming that both enzymes are involved in the production of $S$. coelicolor GBLs.

b) Expression of the S. coelicolor GBL system in E. coli BL21 results in production of SCB2 After identifying the two new genes involved in $S$. coelicolor GBL production, we constructed a GBL production biosynthesis pathway to confirm their roles and to have an 
111 easy production platform of GBLs in E. coli. An expression plasmid containing $s c b A$, $s c b B$ 112 and $s c b C$ under the control of the TetR repressor was constructed. A different TetR113 dependent promoter (tet $A$ for $s c b A^{9}, \mathrm{~Pb} 10$ for $s c b B$ and $\mathrm{Pb} 19$ for $s c b C^{62}$ ) was added in front 114 of each gene, as initial attempts to express the whole operon from a single promoter (tetA) 115 were unsuccessful (data not shown). To facilitate expression of S. coelicolor genes in E. coli 116 BL21, the first ten amino acids of each gene were codon optimised, and were His-tagged. 117 Expression of ScbA and/or ScbC was detected in the soluble and insoluble protein fraction, 118 but not ScbB (Supplementary Fig. S1). In the kanamycin assay (Supplementary Fig. S2), 119 addition of the extract from heterologously expressed ScbA/B/C (pTE1059) in E. coli to the 120 reporter strain induced growth. This extract was then analysed by HPLC-MS/MS (Fig. 3 and 121 Supplementary Fig. S3 and Supplementary Table S4), using an ethyl acetate-methanol extract 122 from S. coelicolor M145 as positive control. In the latter, two peaks are identified in the 123 extracted ion chromatogram (EIC) from the SCB2+Na adduct (theoretical $\mathrm{m} / \mathrm{z}=267.156678$ ) 124 at a retention time of approximately $19 \mathrm{~min}$ after injection. These were assigned as the isomers SCB1 and SCB2, respectively ${ }^{31,34}$. In the extract from E. coli, a peak was detected at the same retention time as observed for SCB2 (mass accuracy $0.68 \mathrm{ppm}$ ). The identity of the compound identified in the E. coli extract was confirmed through tandem MS showing the same fragmentation pattern as the obtained for SCB1 and SCB2 from S. coelicolor M145 (Supplementary Fig. S3). None of the other GBLs produced in S. coelicolor (SCB1 and SCB3) were detected. This can be explained by the fact that the $\beta$-ketoacid used in the first catalytic step towards the production of GBLs derives from fatty acid biosynthesis ${ }^{29,31}$. Fatty acid biosynthesis starts with the decarboxylative condensation of an acyl-CoA primer with malonyl-acyl carrier protein, catalysed by the gene product of $f a b H^{35}$. The S. coelicolor FabH homologue preferentially uses branched acyl-CoA primers for fatty acid production, such as isovaleryl-CoA and isobutyryl-CoA or metylbutyryl-CoA ${ }^{36,37}$, which then results in production of both branched (SCB1 and SCB3) and linear (SCB2) GBLs. However, FabH homologue from E. coli has a strong preference of linear acyl-CoA primers, such as acetylCoA or malonyl-CoA ${ }^{38}$; thus, if the GBL precursors are derived from fatty acid biosynthesis, this would result in exclusive production of linear GBLs (SCB2) in E. coli.

140 To further confirm the role of ScbB and ScbC, single knock-out mutants were generated in 141 the GBL expression plasmid, transformed and expressed in E. coli, and their extracts 142 analysed as described previously (Fig. 3 and Supplementary Fig. S3 and Supplementary 143 Table S4). In the extract from E. coli harbouring scbA/C plasmid (pTE1060)), a peak was 
144 detected in the EIC from the A-factor $+\mathrm{Na}$ adduct (theoretical $\mathrm{m} / \mathrm{z}=265.141028$ ) at 145 approximately $21 \mathrm{~min}$ after injection, the same as A-factor from S. griseus (1.93 ppm). In 146 both extracts from $S$. griseus and E. coli carrying the scbA/C plasmid (pTE1060), an 147 additional broader peak is observed at approximately 20 min after injection. Further analysis 148 through tandem MS showed that both peaks contained fragments consistent with A-factor

149 (Supplementary Fig. S3). In the extract from E. coli carrying scbA/B plasmid (pTE1061), 150 contrary to expectations, no peaks were detected at a mass corresponding to the non-reduced 151 butenolide precursor from A-factor (compound 4), either phosphorylated or not (data not shown). However, an unidentified shunt metabolite was detected at a mass corresponding to A-factor $+\mathrm{Na}$ adduct but eluted at an earlier retention time than A-factor. These results show that by heterologous expression of the three GBL biosynthesis genes, GBLs with linear residue can be produced in $E$. coli.

c) Production of SCB2 in E. coli BL21 is robust through different temperature and medium conditions

159 Synthetic genetic circuits need to be robust under different experimental conditions to allow 160 for predictable rational design of organisms ${ }^{3}$. Important parameters to consider are the temperature and the media conditions at which the synthetic organism is grown ${ }^{39}$. We tested the qualitative analysis of SCB2 production in E. coli at different temperatures and in four different media. Cells containing the $s c b A / B / C$ (pTE1059) plasmid were grown in either M9 minimal medium, LB medium, 2xYT medium or terrific broth (TB) medium and in LB at 20, 25, 30 and $37^{\circ} \mathrm{C}$. SCB2 production was assayed using the kanamycin bioassay. Production was readily detected at assayed temperatures from $20-30{ }^{\circ} \mathrm{C}$; however, the GBL production was not detected with extracts from cells grown at $37^{\circ} \mathrm{C}$ (Fig. 4). This is consistent with previous in vitro enzyme activity results for AfsA ${ }^{29}$ and BarS1 ${ }^{30}$, where a reduction in activity was found for both enzymes after incubation at and above $35{ }^{\circ} \mathrm{C}$. This could be a potential disadvantage when using the GBL system in E. coli. However, the thermal stability and catalytic activity of the GBL biosynthetic enzymes could be achieved through random mutagenesis, as has been previously shown for other enzymes ${ }^{40,41}$. When $E$. coli harbouring $s c b A / B / C$ was expressed in different media, GBLs were detected in all of the tested conditions, both in minimal and rich media. Therefore, SCB2 production is robust in different experimental conditions. 
177 d) Engineering of ScbR to promote solubility in E. coli BL21

178 In S. coelicolor, GBLs promote a switch-like transition to antibiotic production upon binding 179 their cognate receptor. Therefore, after characterising the production of SCB2 in E. coli, we 180 proceeded to characterise the GBL receptor, ScbR, in the heterologous host. Previous reports 26,42,43 identified ScbR, and other GBL receptors, as prone to aggregate and form insoluble

182 inclusion bodies when expressed in an E. coli background. Furthermore, we, and other groups

$183^{44}$, have attempted to crystallise GBL receptors. However, only the structures of distant 184 homologues ${ }^{45,46}$, which are not known to bind GBLs, have been resolved so far. To try to 185 obtain a more soluble version of ScbR, we rationally engineered the structure, based on the 186 available structural information. Using the SWISS-MODEL suite ${ }^{47}$, a model structure of 187 ScbR was generated, using CprB crystal structure (PDB $1 \mathrm{UI5}{ }^{48}$ ) as template, and visualised 188 using the UCSF Chimera package ${ }^{49}$. CprB is a TetR-like DNA-binding protein from $S$. 189 coelicolor M145 with homology to GBL receptor proteins but unable to bind to the GBLs 190 (pseudo-receptor) ${ }^{22}$. The hydrophobic surface of both CprB and ScbR (33\% amino acid 191 identity to CprB) was modelled and compared (Supplementary Fig. S5). As expected, the highly conserved N-terminus of the protein, corresponding to the DNA-binding site of the protein, was similar. However, a hydrophobic patch was identified at the C-terminal end of

194 ScbR, which was not present in CprB. This hydrophobic patch was also not found in the pseudo-receptor ScbR2 (35\% amino acid identity to CprB) (Supplementary Fig. S5). To suggest possible roles of this region it was further interrogated using a docking analysis ${ }^{50}$, which suggested that it might contain a potential GBL binding site (Supplementary Fig. S6).This suggestion would be consistent with an earlier observation ${ }^{51}$ that showed that the addition of GBLs into a crude extract containing ArpA enhanced the solubility of the protein from inclusion bodies. We therefore hypothesized that GBL receptors might form inclusion bodies due to interaction through this hydrophobic, putatively the GBL-binding, region. Thus, to reduce the aggregation propensity, a $6 \mathrm{x}$ arginine tag $\left(\mathrm{Arg}_{6}\right)$ was added at the $\mathrm{C}$ terminus of the protein. Addition of this tag, either at the $\mathrm{N}$ - or the C-terminus, has been shown previously to enhance solubility of proteins without affecting their function ${ }^{52,53}$.

205 Recombinant ScbR-Arg ${ }_{6}$ was expressed from plasmid ScbR-Arg 6 + luxp (pTE1067) and its expression was compared to that of recombinant ScbR expressed from ScbR + luxp (pTE1066) by Western Blot analysis (Fig. 5). In this, ScbR-Arg 6 in pTE1067 was seen to be more soluble compared to ScbR. To confirm whether the soluble ScbR-Arg 6 is functional, a 
gel shift assay using protein crude extract was performed (Fig. 5). This shows that addition of increasing amounts of ScbR-Arg 6 to DNA, results in appearance of two shifted bands which

211 presumably correspond to complexes of one or two ScbR-Arg 6 homodimers bound to the 212 DNA fragment containing operator sequence $\mathrm{O}_{\mathrm{R}}{ }^{26}$ (Fig. 5). This result is consistent with 213 previous reports where ScbR binds its cognate operator sequence as a dimer of homodimers $2144^{45}$ and previous reported gel shift assays using recombinant ScbR ${ }^{26}$. Addition of SCB2 to 215 ScbR-Arg $_{6}$ resulted in release of the repressor from its cognate operator sequence (see 216 below), whereas it resulted in high variable results when SCB2 was added to untagged ScbR 217 (Supplementary Fig. S7). These results suggest that addition of the $\mathrm{Arg}_{6}$ tag at the C-terminal 218 of ScbR results in less aggregation-prone protein while retaining DNA- and GBL-binding 219 activity.

e) Crosstalk evaluation between the GBL and the AHL systems

222 As previously mentioned, a property that synthetic gene circuits aim to achieve is high orthogonality, that is, that two independent genetic devices do not crosstalk ${ }^{3}$. It has been shown that, at physiological conditions, GBLs from Streptomyces only interact with their cognate receptors, although some crosstalk can be achieved at high GBL concentrations, around 200 times higher than the physiological concentration ${ }^{34,55}$. However, to our knowledge, it has not been previously explored whether the GBL system is orthogonal to the more well-established signalling system based on the AHLs from $V$. fisheri and $P$. aeruginosa. These systems are based on the AHLs binding to LuxR-like proteins. Upon binding to their cognate AHLs, the LuxR receptors act as activators and are able to bind to the corresponding operator sequence (e.g., lux box) and recruit the RNA polymerase to induce transcription of a target gene (Fig. 6). On the other hand, the GBL system is based on the binding of the GBLs to the ScbR-like repressors. The ScbR-like receptor binds the operator sequence (e.g., $\mathrm{O}_{\mathrm{R}}$ box) and represses the expression of the target gene. Once bound to cognate GBLs, a conformational change occurs to the receptor and can no longer bind to the operator sequence, which results in the activation of the target gene transcript.

237 Signal and promoter crosstalk were evaluated with plasmid vector BC-A1-002 ${ }^{54}$ and derivatives pTE1063 to pTE1069. These plasmids contain either $\operatorname{luxR}$ or $s c b R$-Arg 6 under the control of a strong constitutive promoter and gfp under the control of the lux promoter (luxp) (BC-A1-002 and pTE1066), the scbA promoter ( $s c b A p){ }^{26}$ (pTE1064 and pTE1069), the $s c b R$ 
241 promoter (scbRp) ${ }^{26}$ (pTE1063 and pTE1068) or the promoter of the activator of the 242 coelimycin biosynthetic cluster (cpkOp) ${ }^{56}$ (pTE1065 and pTE1070). The GFP expression for 243 each construct was measured under different concentrations of 3-oxo- $\mathrm{C}_{6}-\mathrm{HSL}$ (3OC 6 ), 3-oxo$244 \mathrm{C}_{12}$-HSL $\left(3 \mathrm{OC}_{12}\right)$ and purified SCB2, obtained from E. coli supernatant as described in 245 Materials and Methods (Supplementary Fig. S9) to measure the relationship between the 246 input and the response of the synthetic regulatory circuit (Fig. 7, 8).

247 In strains with plasmids containing the $\operatorname{luxR}$, addition of $\mathrm{AHLs}$, either $3 \mathrm{OC}_{6}$ or $3 \mathrm{OC}_{12}$, resulted in activation of the luxp at concentrations above $10^{-11} \mathrm{M}$ or $10^{-10} \mathrm{M}$, respectively, as previously reported ${ }^{10,54}$, highlighting the cross-talk potential between the C6 and C12 AHL systems. However, addition of purified SCB2 only activated luxp at concentrations above 10${ }^{6} \mathrm{M}\left(10^{5}\right.$ times higher concentration of the signal compared to $\left.3 \mathrm{OC}_{6}\right)$. On the other hand, no GFP expression was detected upon addition of any of the three signalling molecules when

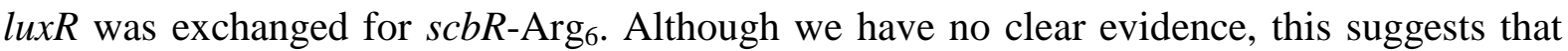
ScbR-Arg ${ }_{6}$ does not bind to the operator sequence of LuxR. If ScbR acted as an inducer, one would expect to see a decrease in GFP expression after the addition of SCB2, and if ScbR acted as a repressor, one would expect to see an increase in GFP expression after addition of SCB2, assuming that in both cases the DNA-binding is responsive to the SCB2 signal. We see neither of these occurring.

The three ScbR-dependent promoters, $s c b R p$, scbAp and $c p k O p$, from S. coelicolor, were assayed to evaluate further the potential crosstalk with the AHL system (plasmids pTE1068 pTE1070). When $g f p$ is placed downstream of any of these promoters in plasmids containing luxR, constitutive expression of GFP was observed, with or without the addition of AHLs or GBL signals. This suggests that the LuxR protein does not interact with any of the tested operator sequences for ScbR, and therefore the promoters are always active (Fig. 7, 8). The GFP expression also corresponded to the strength of the promoters which has been shown before ${ }^{56,57}$ (e.g., scbRp the strongest promoter, followed by $c p k O p$ and $s c b A p$ ). When luxR was exchanged for scbR-Arg , the cells only express $g f p$ at SCB2 concentrations starting from $10^{-9} \mathrm{M}$, reaching a maximum of induction at $10^{-7}-10^{-6} \mathrm{M}$. Addition of more SCB2 beyond this concentration resulted in a decrease in $g f p$ expression for $s c b R p$ or $s c b A p$ (Fig. 7, 8). The potential toxicity of SCB2 in E. coli was discarded as the responsible of this issue, as no decrease in fluorescence was seen in the strains with LuxR and those with cpkOp (Fig. 7, 8) and the final $\mathrm{OD}_{600}$ was independent of the concentration of SCB2 in all samples

273 (Supplementary Fig. S8). This narrow range of activity of the GBL system on these two 
promoters has been previously seen in S. coelicolor, where exogenous addition of SCB1 results in precocious antibiotic production only at a narrow range of concentrations ${ }^{55}$. Further research on the factors that influence this apparent narrow range of GBL induction would be of great interest. Addition of either AHLs to plasmids containing $s c b R-A_{r g}$ resulted in no expression of $g f p$, suggesting that ScbR does not bind to the AHLs and therefore the AHL and GBL signals do not cross-talk at any concentration.

These results show that the GBL system from $S$. coelicolor does not crosstalk with the LuxR system from $V$. fischerii and that neither the AHLs from $V$. fischerii nor those from $P$. aeruginosa bind to ScbR. Furthermore, the GBL system is shown to be highly tightly regulated, resulting in $g f p$ basal expression 4-fold lower than for luxp. This could help create synthetic circuit devices where tight control is required, such as multicellular decision making or multi-state systems ${ }^{21}$. Moreover, the response obtained from the plasmids containing Streptomyces-derived promoters ( $s c b R p, s c b A p$ and $c p k O p$ ) results in relatively low maximum expression of GFP, as opposed to the high levels of expression obtained from luxp, with an approximately 2-fold difference of relative strength between them (Fig. 8). In synthetic microorganisms, especially in those designed to produce speciality chemicals, fine tuning and balancing of all proteins in the biosynthetic pathway has been previously shown to play a crucial role in the titres produced ${ }^{58,59}$, and overly strong induction of the proteins involved in the biosynthetic pathway can result in an impairment of the intracellular metabolite fluxes. The combination of the Streptomyces-derived promoters with the luxp can provide the means to balance and regulate refactored pathways.

\section{f) Induction of the GBL genetic circuits}

297 The purification steps to obtain SCB2 in order to activate gene circuits can be costly and time-consuming, and require specialised equipment that may not be accessible to all. To overcome this limitation of the proposed system, we examined whether addition of crude extract containing SCB2, without the previous purification steps, would result in activation of the circuit. GBL producer strain was grown in LB medium under different temperatures, the GBLs were extracted by a simple ethyl acetate extraction of the culture supernatant, resuspended in different volumes of methanol and assayed against a strain containing plasmid pTE1068 (Fig. 9). Expression of GFP was achieved with extracts from cells grown at $20{ }^{\circ} \mathrm{C}$ enriched 100-fold, and with extracts from cells grown at 25 and $30{ }^{\circ} \mathrm{C}$ enriched 500 -fold. 
306 These results show that signalling molecule can be obtained to activate circuits without any need of prior complicated purification steps (e.g., by use of HPLC), making it an accessible and versatile tool.

309 Interestingly, as methanol extracts are added in a 1:100 dilution to the culture with strains 310 containing the reporter plasmid pTE1068, addition of extracts enriched 100-fold corresponds

311 to a concentration of SCB2 similar to that present in the natural supernatant of the producer 312 strain before extraction. This suggests that the whole GBL system (receptor and synthases) 313 could also be used in vivo, albeit some modifications to enhance thermal stability and 314 enzymatic activity might be needed, depending on the application (e.g.; use in human cells).

315 This would then allow to generate complex circuit systems by integrating the whole system 316 inside a single cell to program a determined routine or in different cells (e.g., a sender and a 317 receiver system) to generate a synthetic ecosystems.

\section{8 g) Towards establishing butyrolactone signalling circuits for synthetic biology}

319 The generation of novel regulatory circuits that allow the assembly of predictable genetic 320 devices is one of the major challenges of synthetic biology. Currently, AHL-based circuits 321 are one of the popular choices considered when designing such devices. Here, we report the 322 first steps towards the design of the GBL system as a complementary tool for synthetic regulatory circuits. The results presented are the proof-of-concept that the GBL system from

324 Streptomyces can be used in E. coli to control synthetic gene expression. An interesting area 325 of future research will be the further optimisation of the GBL biosynthetic genes through 326 directed evolution to obtain more active and thermally stable versions. This would allow 327 expression of the whole system in mammalian cells, in which GBLs have already been found 328 to be active ${ }^{60}$. Also of great interest would be the diversification of the GBL toolbox by exploiting the modular nature of the GBL biosynthetic pathway, increasing the amount of orthogonal signal systems available to control gene expression. Finally, the interesting property that addition of high SCB2 concentrations results in inhibition of GFP expression could potentially be used to develop genetic band-pass filters that allow expression of synthetic devices only within a narrow range of inducer concentrations. 
a) Bacterial strains and Plasmids.

337 Bacterial strains, oligonucleotides and plasmids used in this study are listed in Supplementary

338 Tables S1-S3. E. coli DH5 $\alpha$ strain was used as a host for plasmid construction and maintenance; E. coli BL21 was used for protein expression and GBL production. All oligonucleotides used for PCR amplification and sequencing were synthesized by IDT.

To construct a deletion mutant of $s c b B$ in S. coelocolor, a 3.6 kb SalI-SphI fragment containing scbB (sco6264) was subcloned into pUC19 to generate pCK1. pCK1 was digested with HincII and then $1.1 \mathrm{~kb}$ of thiostrepton-resistance gene (tsr) was inserted. The construct was confirmed to have the desired deletion by DNA sequencing and restriction enzyme digestion. From the resulting plasmid, the BamHI-HindIII fragment was subcloned into the BamHI-HindIII-digested conjugative vector pKC1132 to generate pCK2. The plasmid pCK2 was transferred into S. coelicolor by conjugation via E. coli donor ET12567 (pUZ8002) to generate the $s c b B$ mutant strain LW107 ( $\triangle s c b B)$. A deletion mutant of scbC (sco6267), LW108, in S. coelicolor was constructed by inserting scbC with an apramycin resistance gene and the oriT on cosmid AH10 using the PCR-targeting technology ${ }^{61}$. Both the $s c b B$ and $s c b C$ deletion mutants have been verified by sequencing.

352

To construct plasmid pTE1059 (scbA/B/C), $s c b A, s c b B$ and $s c b C$ were amplified from $S$. coelicolor M145 genomic DNA using primer pairs scbA_His_5/scbA_3, scbB_5/scbB_His_3 and scbC_5/scbC_His_3, respectively. Then these were modified with primer pairs scbA_mod_F/scbA_3, scbB_mod_F/scbB_His_3 and scbC_mod_F/scbC_His_3; and then assembled using Infusion (CloneTech) on plasmid $\mathrm{pBbA} 2 \mathrm{k}^{9}$, previously digested with EcoRI and XhoI, together with DNA fragments containing promoters $\mathrm{Pb} 10$ and $\mathrm{Pb} 19{ }^{62}$, built through annealing of primers Pb10_5/3 and Pb19_5/3. Plasmids pTE1060 (scbA/C) and pTE1061 (scbA/B) were constructed by restriction digestion of pTE1059 with NotI and ApaI, respectively, followed by religation.

361 Strain S. coelicolor LW94 was built by integration of reporter plasmid pTE1062, which is plasmid pTE134 ${ }^{34}$ with $s c b R$ in the same orientation as the kanamycin resistant gene (neo).

Plasmid BC-A1-002 was a gift from Brian Chow (Addgene plasmid \# 78689). To build plasmid pTE1066 or pTE1067, BC-A1-002 was digested with EcoRI and NotI and ligated with EcoRI and NotI digested PCR product containing scbR (primer pair: scbR_5/3) or scbRArg $_{6}$ (primer pair: scbR_5 and scbRarg6_3). Exchange of promoter regions was performed 
either via whole plasmid amplification, followed by religation (plasmids with $s c b R p$ and $s c b A p$ ) or by ligating a fragment generated through primer annealing to a HindIII and SpeIdigested reporter plasmids (plasmids with $c p k O p$ ). All plasmids were confirmed by sequencing.

\section{b) Culture media and conditions}

372 Luria Broth (LB) medium containing $10 \mathrm{~g} / \mathrm{L}$ peptone, $5 \mathrm{~g} / \mathrm{L}$ yeast extract, and $10 \mathrm{~g} / \mathrm{L} \mathrm{NaCl}$ was used for standard bacterial growth and GBL production. GBL input-response relationship was measured using M9 minimal medium (M9) containing 1X M9 salts (Sigma), $0.4 \%$ glucose, $2 \mathrm{mM} \mathrm{MgSO}_{4}$ and $0.1 \mathrm{mM} \mathrm{CaCl}_{2}, \mathrm{pH}$ 7.0. To evaluate GBL production under different medium, LB and M9 medium were used as previously described; as well as Terrific Broth (TB) containing $12 \mathrm{~g} / \mathrm{L}$ Tryptone, $24 \mathrm{~g} / \mathrm{L}$ yeast extract, 0.4 \%(v/v) glycerol, and 1X phosphate salts (0.17 $\mathrm{M} \mathrm{KH}_{2} \mathrm{PO}_{4}, 0.72 \mathrm{M} \mathrm{K}_{2} \mathrm{HPO}_{4}, \mathrm{pH}$ 7.0); and 2xYT medium (2xYT) containing $16 \mathrm{~g} / \mathrm{L}$ Bacto Tryptone, $10 \mathrm{~g} / \mathrm{L}$ Bacto Yeast Extract and 5 g/L NaCl, pH 7.0. Chloramphenicol and kanamycin were supplemented into the media, where appropriate, at concentrations of $30 \mu \mathrm{g} / \mathrm{mL}$ and $50 \mu \mathrm{g} / \mathrm{mL}$, respectively.

c) Expression of the GBL biosynthetic pathway in E. coli

383 Single colonies of E. coli BL21 strains carrying expression plasmids with the GBL synthases (pA15 origin of replication, $\sim 5$ copies per cell) were grown at $37{ }^{\circ} \mathrm{C}$ for $16-18 \mathrm{~h}$ in $\mathrm{LB}$ supplemented with $50 \mu \mathrm{g} / \mathrm{mL}$ of kanamycin. Samples were diluted to an $\mathrm{OD}_{600 \mathrm{~nm}}$ of 0.05 in LB medium without antibiotics and grown at $37^{\circ} \mathrm{C}$ until they reached an $\mathrm{OD}_{600 \mathrm{~nm}}$ of $0.3-0.4$, when protein expression was induced with $50 \mathrm{nM}$ anhydrotetracycline (aTc) and performed for $5 \mathrm{~h}$ at $25^{\circ} \mathrm{C}$. Cells were pelleted at $10,000 \mathrm{xg}$ and $4{ }^{\circ} \mathrm{C}$ for $10 \mathrm{~min}$ and resuspended in lysis buffer $\mathrm{C}(150 \mathrm{mM}$ Tris- $\mathrm{HCl} \mathrm{pH}$ 7.4, $200 \mathrm{mM} \mathrm{NaCl}$ and $1 \mathrm{mM}$ DTT, cOmplete $^{\mathrm{TM}}$ tablet (Sigma)) and homogenised by sonication. The soluble protein fraction was recovered after centrifugation at $17,000 \mathrm{xg}$ and $4{ }^{\circ} \mathrm{C}$ for $20 \mathrm{~min}$ and the insoluble fraction was resuspended in MilliQ grade $\mathrm{H}_{2} \mathrm{O}$.

When evaluating the robustness of the GBL biosynthetic pathway under different experimental conditions, E. coli cells containing the $s c b A / B / C$ (pTE1059) plasmid and originated from the same colony, were grown at $25^{\circ} \mathrm{C}$ in either M9, LB, 2xYT or TB and in 
398 Extraction of GBLs from S. coelicolor strains grown in solid cultures was performed as previously described ${ }^{63}$. For the extraction of GBL or intermediate metabolites from E. coli BL21, single colonies of E. coli BL21 strains carrying the corresponding plasmids were grown and expressed as described in the previous section. After centrifugation, the supernatant was mixed with an equal volume of ethyl acetate and vigorously mixed. Organic phase was separated, dried with $\mathrm{MgSO}_{4}$ and the solvent was removed at room temperature and resuspended in 1:100 volume of methanol. In order to purify SCB2, $1.5 \mathrm{~L}$ of $E$. coli BL21/pTE1059 (scbA/B/C) were grown as previously described, with induction at $20^{\circ} \mathrm{C}$ for 16 - 18 h. Purification was performed on a $\mathrm{C}_{18}$ reverse phase column (Kinetex 5 um C18 100 $\AA 250$ x $21.2 \mathrm{~mm}$ ) on a preparative HPLC (Agilent 1250 Infinity) equipped with a UV detector set at $210 \mathrm{~nm}$ and $254 \mathrm{~nm}$ and with a flow rate of $5 \mathrm{~mL} / \mathrm{min}$. A maximum volume of $5 \mathrm{~mL}$ were loaded onto the column and eluted in a linear gradient of 5-100 \% methanol +0.1 $\%$ formic acid. Samples were collected every minute and subjected to bioassay. Positive samples were pooled, the solvent removed at room temperature and diluted in $5 \mathrm{~mL}$ of methanol. These were loaded again onto the column and eluted in a linear gradient of 5-100

$413 \%$ of acetonitrile $+0.1 \%$ formic acid. Samples were collected every minute and subjected to bioassay. Active samples were pooled, the solvent removed at room temperature and diluted in $5 \mathrm{~mL}$ of methanol. This procedure was repeated four times and all samples resuspended in methanol pooled together. The solvent was removed and the samples were weighted, resulting in a total of $15.2 \mathrm{mg}$ of extract obtained. To assess the purity of the sample, the extract was diluted in $1 \mathrm{~mL}$ of methanol and subjected to bioassay in serial dilutions of 2fold. The minimum active dilution was considered to contain $0.05 \mu \mathrm{g} / \mu \mathrm{L}$ of SCB2, as previously determined by Hsiao et al. ${ }^{34}$. This yielded an active concentration of $3.2 \mathrm{mg}$, resulting in a yield of $2.2 \mathrm{mg} / \mathrm{L}$ culture.

\section{e) Kanamycin Bioassays}

423 Kanamycin bioassays were performed as previously described (63). Briefly, a lawn of $S$. 424 coelicolor LW94 was prepared in DNAgar plates supplemented with $5 \mu \mathrm{g} / \mathrm{mL}$ of kanamycin 425 by diluting $2.6 \times 10^{6}$ spores / $100 \mu \mathrm{L}$ sterile deionised water and evenly spreading across the 426 plate. The plates were allowed to dry for three minutes at room temperature and then 2-3 $\mu \mathrm{L}$ 427 of methanol extract were spotted on the plate and allowed to dry at room temperature. Plates 428 were incubated at $30{ }^{\circ} \mathrm{C}$ for 2 - 3 days and growth was monitored every $12 \mathrm{~h}$. 
430 A volume of $100 \mu \mathrm{L}$ of sample (e.g., GBL extract) were diluted 1:2 with HPLC water (total volume $200 \mu \mathrm{L}$ ), centrifuged at 17,000 $\mathrm{xg}$ for $15 \mathrm{~min}$ to remove any aggregates formed and transferred $150 \mu \mathrm{L}$ of the resulting product into a glass vial. A total of $15 \mu \mathrm{L}$ were injected per sample. The solvents used were $\mathrm{A}: \mathrm{H}_{2} \mathrm{O}+0.1 \%$ formic acid and $\mathrm{B}$ : $\mathrm{MeOH}+0.1 \%$ formic acid. Both solvents were HPLC grade, from Sigma. The run conditions were 5 min isocratic A:B (95:5) then gradient of 25 min to A:B (5:95), followed by isocratic 5 min A:B (5:95) in an Accucore UHPLC $\mathrm{C}_{18}$ reverse phase column (Thermo Fisher) and a Q Exactive (Thermo Fisher). The ionization conditions were in positive ion mode at a spray voltage of $1.5 \mathrm{kV}$.

g) ScbR expression

Expression of ScbR was analysed using E. coli BL21 harbouring plasmids ScbR + luxp (pTE1066) or ScbR-Arg 6 + luxp (pTE1067). Single colonies were grown for $16-18 \mathrm{~h}$ at 37 ${ }^{\circ} \mathrm{C}$ in LB medium supplemented with $30 \mu \mathrm{g} / \mathrm{mL}$ of chloramphenicol. Cells were diluted 1:100 in LB without antibiotics and grown at $30^{\circ} \mathrm{C}$ for $6 \mathrm{~h}$. Cells were centrifuged at 10,000 $\mathrm{xg}$ and $4{ }^{\circ} \mathrm{C}$ for $10 \mathrm{~min}$, the supernatant was discarded and the pellet homogenised by sonication in buffer $\mathrm{A}^{64}$ (50 mM sodium phosphate buffer $\mathrm{pH}$ 7.0, cOmplete ${ }^{\mathrm{TM}}$ tablet (Sigma)). The soluble protein fraction was recovered from the supernatant after centrifugation for $20 \mathrm{~min}$ at $17,000 \mathrm{xg}$ and $4{ }^{\circ} \mathrm{C}$ and the pelleted insoluble fraction was resuspended in MiliQ grade $\mathrm{H}_{2} \mathrm{O}$.

h) SDS-PAGE and Western Blot

To assess protein expression, crude extracts (either soluble or insoluble fractions) were 449 resolved through SDS-PAGE (10\%(w/v), BioRad) according to Laemmli’s procedure ${ }^{65}$.

450 Resolved bands were visualised by Coomassie blue staining (Expedeon). For Western analysis, proteins resolved by SDS-PAGE gels were transferred to a polyvinylidene fluoride (PVDF) membrane by semi-dry blotting. Immunodetection of His-tagged ScbA, ScbB or ScbC was performed using mouse anti-His (Sigma H1029) as primary antibody and IRDye ${ }^{\circledR}$ conjugated anti-mouse IgG (Abcam ab216772) as secondary antibody, and visualised using LI-COR. Immunodetection of ScbR was carried out using rabbit antiserum raised against ScbR ${ }^{66}$ as primary antibody and HRP-conjugated goat anti-rabbit IgG (BioRad) as secondary antibody. The substrate for chemiluminescent detection was Amersham ECL Prime (GE Healthcare) and was visualised using a GeneGnome (Syngene). 
460 Gel shift assays were performed as previously described ${ }^{62}$, using the Roche DIG Gel Shift 461 Kit (Roche). The scbRp was amplified from genomic DNA using primers scbRp_5/3, generating a 144 bp fragment that was labelled with DIG according to manufacturer's protocol. For each reaction, 25 ng of labelled probe were used. Where appropriate, SCB2 extracts were added to the mixture prior incubation. DIG-labelled DNA fragments were immunodetected using antibody mouse anti-DIG (Abcam ab116590) as primary antibody and IRDye ${ }^{\circledR}$-conjugated anti-mouse IgG (Abcam ab216772) as secondary antibody, and visualised using LI-COR.

\section{j) Relationship between signal input and response of GBL and AHL receptors}

469

Single colonies of E. coli BL21 cells containing appropriate plasmids were grown for 16 - 18 $\mathrm{h}$ in LB medium with $30 \mu \mathrm{g} / \mathrm{mL}$ of chloramphenicol and then diluted 1:100 in M9 without antibiotics and grown at $37{ }^{\circ} \mathrm{C}$ until an $\mathrm{OD}_{600} 0.3-0.4$, where they were aliquoted into 500 $\mu \mathrm{L}$ aliquots and supplemented with $1 \%(\mathrm{v} / \mathrm{v})$ of the serial dilutions of either $3 \mathrm{OC}_{6}-\mathrm{HSL}$ (Sigma-Aldrich), $3 \mathrm{OC}_{12}$-HSL (Sigma-Aldrich) or SCB2 (this study) in methanol. Samples were grown at $30{ }^{\circ} \mathrm{C}$ for $20 \mathrm{~h}$ and then transferred into a 96-well plate in triplicate $(150 \mu \mathrm{L}$ sample/well). $\mathrm{OD}_{600}$ and GFP fluorescence (excitation, $466 \mathrm{~nm}$; emission, $511 \mathrm{~nm}$ ) were measured in triplicate in a ClarioStar (BMG Labtech) plate reader. Each measurement was performed in biological triplicate.

\section{k) Structural model of ScbR and docking}

480 The model structure of ScbR was generated using the SWISS-MODEL suite ${ }^{47}$ and CprB crystal structure (PDB $1 \mathrm{UI} 5^{48}$ ) as template. The resulting structure was exported as PDB file and visualised using the UCSF Chimera package ${ }^{49}$. The protein surface was generated using default settings and the hydrophobic regions highlighted with the kdHydrophobicity command line option. Dockings were performed using Autodock Vina software under standard configuration and a grid previously defined with Autodock Tools ${ }^{50}$, and were either a broad grid covering the whole protein surface or a more constraint grid covering only the Cterminus end of the protein. 
489 Supporting Information. Table S1: Bacterial strains; Table S2: Plasmids; Table S3:

490 Oligonucleotides; Figure S1: Western Blot analysis of ScbA, ScbB and ScbC protein

491 expression; Figure S2: Kanamycin bioassay to assess production of GBLs in E. coli

492 containing plasmids for the expression of ScbA/B/C; Table S4: MS1 adducts of SCB2 and

493 A-factor; Figure S3: Tandem MS of SCB2 and A-factor; Figure S4: Structural Model of

494 ScbR; Figure S5: Docking results; and Figure S6: Purified SCB2 HPLC-MS analysis.

495

496 Author information

497 Author list:

498 Marc Biarnes-Carrera ${ }^{1}$, Chang-Kwon Lee ${ }^{2,4}$, Takuya Nihira ${ }^{2,3}$, Rainer Breitling ${ }^{1}$ and Eriko 499 Takano $^{1}$

500 Affiliation:

$501{ }^{1}$ Manchester Centre for Synthetic Biology of Fine and Speciality Chemicals 502 (SYNBIOCHEM), Manchester Institute of Biotechnology, School of Chemistry, Faculty of 503 Science and Engineering, University of Manchester, 131 Princess Street, Manchester M1 504 7DN, United Kingdom.

$505{ }^{2}$ International Center for Biotechnology, Osaka University, 2-1 Yamadaoka, Suita, Osaka 506 565-0871, Japan

$507{ }^{3}$ Mahidol University-Osaka University Collaborative Research Center for Bioscience and 508 Biotechnology, Faculty of Science, Mahidol University, Rama VI Rd., Bangkok 10400, 509 Thailand

$510 \quad{ }^{4}$ Present address: Mong-Go Food Co., Ltd., Changwon 641-847, Republic of Korea

\section{Author Contributions}

513 MBC and CKL performed the experiments. MBC, TN and ET designed the experiments.

514 MBC, TN, RB and ET analysed the results and wrote the manuscript. All authors have read,

515 edited and approved the manuscript.

\section{Corresponding Author}

517 *E-mail: eriko.takano@manchester.ac.uk. 
The authors declare no competing financial interest.

\section{Acknowledgments:}

MBC was supported by the School of Chemistry, Faculty of Science and Engineering, University of Manchester. Plasmid BC-A1-002 was a gift from Brian Chow. This is a contribution from the Manchester Centre for Synthetic Biology of Fine and Speciality Chemicals (SYNBIOCHEM) and acknowledges the Biotechnology and Biological Sciences Research Council (BBSRC) and Engineering and Physical Sciences Research Council (EPSRC) for financial support (Grant No. BB/M017702/1).

\section{References}

1. Khalil, A. S., and Collins, J. J. (2010) Synthetic biology: applications come of age, Nat. Rev. Genetics

2. Wang, B., Kitney, R. I., Joly, N., and Buck, M. (2011) Engineering modular and orthogonal genetic logic gates for robust digital-like synthetic biology, Nat. Commun. 2, 508.

3. Bradley, R. W., Buck, M., and Wang, B. (2016) Tools and Principles for Microbial Gene Circuit Engineering, J. Mol. Biol. 428, 862-888.

4. Davis, J. H., Rubin, A. J., and Sauer, R. T. (2011) Design, construction and characterization of a set of insulated bacterial promoters, Nucleic Acids Res. 39, 1131-1141.

5. Alper, H., Fischer, C., Nevoigt, E., and Stephanopoulos, G. (2005) Tuning genetic control through promoter engineering, Proc. Natl. Acad. Sci. U. S. A. 102, 12678-12683.

6. Salis, H. M., Mirsky, E. A., and Voigt, C. A. (2009) Automated design of synthetic ribosome binding sites to control protein expression, Nat. Biotechnol. 27, 946-950.

7. Andersen, J. B., Sternberg, C., Poulsen, L. K., Bjorn, S. P., Givskov, M., and Molin, S. (1998) New unstable variants of green fluorescent protein for studies of transient gene expression in bacteria, Appl. Environ. Microbiol. 64, 2240-2246.

8. Purcell, O., Grierson, C. S., Bernardo, M., and Savery, N. J. (2012) Temperature dependence of ssrAtag mediated protein degradation, J. Biol. Eng. 6, 10.

9. $\quad$ Lee, T. S., Krupa, R. A., Zhang, F., Hajimorad, M., Holtz, W. J., Prasad, N., Lee, S. K., and Keasling, J. D. (2011) BglBrick vectors and datasheets: A synthetic biology platform for gene expression, J. Biol. Eng. 5, 12.

10. Scott, S. R., and Hasty, J. (2016) Quorum Sensing Communication Modules for Microbial Consortia, ACS Synth. Biol. 5, 969-977.

11. Li, Z., and Nair, S. K. (2012) Quorum sensing: how bacteria can coordinate activity and synchronize their response to external signals?, Protein Sci. 21, 1403-1417.

12. Danino, T., Mondragon-Palomino, O., Tsimring, L., and Hasty, J. (2010) A synchronized quorum of genetic clocks, Nature 463, 326-330.

13. Cornforth, D. M., Popat, R., McNally, L., Gurney, J., Scott-Phillips, T. C., Ivens, A., Diggle, S. P., and Brown, S. P. (2014) Combinatorial quorum sensing allows bacteria to resolve their social and physical environment, Proc. Natl. Acad. Sci. U. S. A. 111, 4280-4284.

14. Wu, F., Menn, D. J., and Wang, X. (2014) Quorum-sensing crosstalk-driven synthetic circuits: from unimodality to trimodality, Chem. Biol. 21, 1629-1638. 
15. Smith, R. S., and Iglewski, B. H. (2003) Pseudomonas aeruginosa quorum sensing as a potential antimicrobial target, J. Clin. Invest. 112, 1460-1465.

16. Dong, Y. H., and Zhang, L. H. (2005) Quorum sensing and quorum-quenching enzymes, J. Microbiol. 43, 101-109.

17. Yang, F., Wang, L. H., Wang, J., Dong, Y. H., Hu, J. Y., and Zhang, L. H. (2005) Quorum quenching enzyme activity is widely conserved in the sera of mammalian species, FEBS Lett. 579, 3713-3717.

18. Ozer, E. A., Pezzulo, A., Shih, D. M., Chun, C., Furlong, C., Lusis, A. J., Greenberg, E. P., and Zabner, J. (2005) Human and murine paraoxonase 1 are host modulators of Pseudomonas aeruginosa quorumsensing, FEMS Microbiol. Lett. 253, 29-37.

19. Bansal, K., Yang, K., Nistala, G. J., Gennis, R. B., and Bhalerao, K. D. (2010) A positive feedbackbased gene circuit to increase the production of a membrane protein, J. Biol. Eng. 4, 6.

20. Cimermancic, P., Medema, M. H., Claesen, J., Kurita, K., Wieland Brown, L. C., Mavrommatis, K., Pati, A., Godfrey, P. A., Koehrsen, M., Clardy, J., Birren, B. W., Takano, E., Sali, A., Linington, R. G., and Fischbach, M. A. (2014) Insights into secondary metabolism from a global analysis of prokaryotic biosynthetic gene clusters, Cell 158, 412-421.

21. Biarnes-Carrera, M., Breitling, R., and Takano, E. (2015) Butyrolactone signalling circuits for synthetic biology, Curr. Opin. Chem. Biol. 28, 91-98.

22. Takano, E. (2006) Gamma-butyrolactones: Streptomyces signalling molecules regulating antibiotic production and differentiation, Curr. Opin. Microbiol. 9, 287-294.

23. Zou, Z., Du, D., Zhang, Y., Zhang, J., Niu, G., and Tan, H. (2014) A gamma-butyrolactone-sensing activator/repressor, JadR3, controls a regulatory mini-network for jadomycin biosynthesis, Mol. Microbiol. 94, 490-505.

24. Recio, E., Colinas, A., Rumbero, A., Aparicio, J. F., and Martin, J. F. (2004) PI factor, a novel type quorum-sensing inducer elicits pimaricin production in Streptomyces natalensis, J. Biol. Chem. 279, 41586-41593.

25. Nodwell, J. R. (2014) Are you talking to me? A possible role for gamma-butyrolactones in interspecies signalling, Mol. Microbiol. 94, 483-485.

26. Takano, E., Chakraburtty, R., Nihira, T., Yamada, Y., and Bibb, M. J. (2001) A complex role for the gamma-butyrolactone SCB1 in regulating antibiotic production in Streptomyces coelicolor A3(2), Mol. Microbiol. 41, 1015-1028.

27. Lee, K. M., Lee, C. K., Choi, S. U., Park, H. R., Kitani, S., Nihira, T., and Hwang, Y. I. (2005) Cloning and in vivo functional analysis by disruption of a gene encoding the gamma-butyrolactone autoregulator receptor from Streptomyces natalensis, Arch. Microbiol. 184, 249-257.

28. Kinoshita, H., Ipposhi, H., Okamoto, S., Nakano, H., Nihira, T., and Yamada, Y. (1997) Butyrolactone autoregulator receptor protein (BarA) as a transcriptional regulator in Streptomyces virginiae, J. Bacteriol. 179, 6986-6993.

29. Kato, J. Y., Funa, N., Watanabe, H., Ohnishi, Y., and Horinouchi, S. (2007) Biosynthesis of gammabutyrolactone autoregulators that switch on secondary metabolism and morphological development in Streptomyces, Proc. Natl. Acad. Sci. U. S. A. 104, 2378-2383.

30. Shikura, N., Yamamura, J., and Nihira, T. (2002) barS1, a gene for biosynthesis of a gammabutyrolactone autoregulator, a microbial signaling molecule eliciting antibiotic production in Streptomyces species, J. Bacteriol. 184, 5151-5157.

31. Sidda, J. D., Poon, V., Song, L., Wang, W., Yang, K., and Corre, C. (2016) Overproduction and identification of butyrolactones SCB1-8 in the antibiotic production superhost Streptomyces M1152, Org. Biomol. Chem. 14, 6390-6393.

32. Hsiao, N. H., Soding, J., Linke, D., Lange, C., Hertweck, C., Wohlleben, W., and Takano, E. (2007) ScbA from Streptomyces coelicolor A3(2) has homology to fatty acid synthases and is able to synthesize gamma-butyrolactones, Microbiology 153, 1394-1404.

33. Lee, Y. J., Kitani, S., Kinoshita, H., and Nihira, T. (2008) Identification by gene deletion analysis of barS2, a gene involved in the biosynthesis of gamma-butyrolactone autoregulator in Streptomyces virginiae, Arch. Microbiol. 189, 367-374.

34. Hsiao, N. H., Nakayama, S., Merlo, M. E., de Vries, M., Bunet, R., Kitani, S., Nihira, T., and Takano, E. (2009) Analysis of two additional signaling molecules in Streptomyces coelicolor and the development of a butyrolactone-specific reporter system, Chem. Biol. 16, 951-960.

35. Lai, C. Y., and Cronan, J. E. (2003) Beta-ketoacyl-acyl carrier protein synthase III (FabH) is essential for bacterial fatty acid synthesis, J. Biol. Chem. 278, 51494-51503.

36. Choi, K. H., Heath, R. J., and Rock, C. O. (2000) beta-ketoacyl-acyl carrier protein synthase III (FabH) is a determining factor in branched-chain fatty acid biosynthesis, J. Bacteriol. 182, 365-370. 
37. Li, Y., Florova, G., and Reynolds, K. A. (2005) Alteration of the fatty acid profile of Streptomyces coelicolor by replacement of the initiation enzyme 3-ketoacyl acyl carrier protein synthase III (FabH), J. Bacteriol. 187, 3795-3799.

38. Tsay, J. T., Oh, W., Larson, T. J., Jackowski, S., and Rock, C. O. (1992) Isolation and characterization of the beta-ketoacyl-acyl carrier protein synthase III gene $(\mathrm{fabH})$ from Escherichia coli K-12, The J. Biol. Chem. 267, 6807-6814.

39. Cardinale, S., and Arkin, A. P. (2012) Contextualizing context for synthetic biology--identifying causes of failure of synthetic biological systems, Biotechnol. J. 7, 856-866.

40. Song, J. K., and Rhee, J. S. (2000) Simultaneous enhancement of thermostability and catalytic activity of phospholipase A(1) by evolutionary molecular engineering, Appl. Environ. Microbiol. 66, 890-894.

41. Soh, L. M. J., Mak, W. S., Lin, P. P., Mi, L., Chen, F. Y., Damoiseaux, R., Siegel, J. B., and Liao, J. C. (2017) Engineering a Thermostable Keto Acid Decarboxylase Using Directed Evolution and Computationally Directed Protein Design, ACS Synth. Biol. 6, 610-618.

42. Yang, Y. H., Kim, T. W., Park, S. H., Lee, K., Park, H. Y., Song, E., Joo, H. S., Kim, Y. G., Hahn, J. S., and Kim, B. G. (2009) Cell-free Escherichia coli-based system to screen for quorum-sensing molecules interacting with quorum receptor proteins of Streptomyces coelicolor, Appl. Environ. Microbiol. 75, 6367-6372.

43. Kudo, N., Kimura, M., Beppu, T., and Horinouchi, S. (1995) Cloning and characterization of a gene involved in aerial mycelium formation in Streptomyces griseus, J. Bacteriol. 177, 6401-6410.

44. Horinouchi, S., and Beppu, T. (2007) Hormonal control by A-factor of morphological development and secondary metabolism in Streptomyces, Proc. Jpn. Acad., Ser. B Phys. Biol. Sci. 83, 277-295.

45. Bhukya, H., Bhujbalrao, R., Bitra, A., and Anand, R. (2014) Structural and functional basis of transcriptional regulation by TetR family protein CprB from S. coelicolor A3(2), Nucleic Acids Res. 42, 10122-10133.

46. Mohd-Sharif, N., Shaibullah, S., Givajothi, V., Tan, C. S., Ho, K. L., Teh, A. H., Baharum, S. N., Waterman, J., and Ng, C. L. (2017) Crystallization and X-ray crystallographic analysis of recombinant TylP, a putative gamma-butyrolactone receptor protein from Streptomyces fradiae, Acta Crystallogr., Sect. F: Struct. Biol. Commun. 73, 109-115.

47. Arnold, K., Bordoli, L., Kopp, J., and Schwede, T. (2006) The SWISS-MODEL workspace: a webbased environment for protein structure homology modelling, Bioinformatics 22, 195-201.

48. Natsume, R., Ohnishi, Y., Senda, T., and Horinouchi, S. (2004) Crystal structure of a gammabutyrolactone autoregulator receptor protein in Streptomyces coelicolor A3(2), J. Mol. Biol. 336, 409419.

49. Pettersen, E. F., Goddard, T. D., Huang, C. C., Couch, G. S., Greenblatt, D. M., Meng, E. C., and Ferrin, T. E. (2004) UCSF Chimera--a visualization system for exploratory research and analysis, $J$. Comput. Chem. 25, 1605-1612.

50. Trott, O., and Olson, A. J. (2010) AutoDock Vina: improving the speed and accuracy of docking with a new scoring function, efficient optimization, and multithreading, J. Comput. Chem. 31, 455-461.

51. Onaka, H., Nakagawa, T., and Horinouchi, S. (1998) Involvement of two A-factor receptor homologues in Streptomyces coelicolor A3(2) in the regulation of secondary metabolism and morphogenesis, Mol. Microbiol. 28, 743-753.

52. Fuchs, S. M., and Raines, R. T. (2005) Polyarginine as a multifunctional fusion tag, Protein Sci. 14, 1538-1544.

53. Kato, A., Maki, K., Ebina, T., Kuwajima, K., Soda, K., and Kuroda, Y. (2007) Mutational analysis of protein solubility enhancement using short peptide tags, Biopolymers 85, 12-18.

54. Magaraci, M. S., Bermudez, J. G., Yogish, D., Pak, D. H., Mollov, V., Tycko, J., Issadore, D., Mannickarottu, S. G., and Chow, B. Y. (2016) Toolbox for Exploring Modular Gene Regulation in Synthetic Biology Training, ACS Synth. Biol. 5, 781-785.

55. Takano, E., Nihira, T., Hara, Y., Jones, J. J., Gershater, C. J., Yamada, Y., and Bibb, M. (2000) Purification and structural determination of SCB1, a gamma-butyrolactone that elicits antibiotic production in Streptomyces coelicolor A3(2), J. Biol. Chem. 275, 11010-11016.

56. Takano, E., Kinoshita, H., Mersinias, V., Bucca, G., Hotchkiss, G., Nihira, T., Smith, C. P., Bibb, M., Wohlleben, W., and Chater, K. (2005) A bacterial hormone (the SCB1) directly controls the expression of a pathway-specific regulatory gene in the cryptic type I polyketide biosynthetic gene cluster of Streptomyces coelicolor, Mol. Microbiol. 56, 465-479.

57. Gottelt, M., Kol, S., Gomez-Escribano, J. P., Bibb, M., and Takano, E. (2010) Deletion of a regulatory gene within the cpk gene cluster reveals novel antibacterial activity in Streptomyces coelicolor A3(2), Microbiology 156, 2343-2353 
58. Ajikumar, P. K., Xiao, W. H., Tyo, K. E., Wang, Y., Simeon, F., Leonard, E., Mucha, O., Phon, T. H., overproduction in Escherichia coli, Science 330, 70-74.

59. Sung, M., Yoo, S., Jun, R., Lee, J., Lee, S., and Na, D. (2016) Optimization of phage lambda promoter strength for synthetic small regulatory RNA-based metabolic engineering, Biotechnol. Bioproc. E 21, 483-490.

60. Weber, W., Schoenmakers, R., Spielmann, M., El-Baba, M. D., Folcher, M., Keller, B., Weber, C. C., Link, N., van de Wetering, P., Heinzen, C., Jolivet, B., Sequin, U., Aubel, D., Thompson, C. J., and Fussenegger, M. (2003) Streptomyces-derived quorum-sensing systems engineered for adjustable transgene expression in mammalian cells and mice, Nucleic Acids Res. 31, e71.

61. Gust, B., Challis, G.L., Fowler, K., Kieser, T., and Chater, K.F. (2003) PCR-targeted Streptomyces gene replacement identifies a protein domain needed for biosynthesis of the sesquiterpene soil odor geosmin, Proc. Natl. Acad. Sci. U. S. A. 100,1541-1546.

62. Cox, R. S., Surette, M. G., and Elowitz, M. B. (2007) Programming gene expression with combinatorial promoters, Mol. Syst. Biol. 3, 145.

63. Biarnes-Carrera, M., Breitling, R., and Takano, E. (2018) Chapter 10. Detection and quantification of butyrolactones from Streptomyces. In Quorum Sensing: Methods and Protocols, Methods in Molecular Biology (Leoni, L., and Rampioni, G., Eds.), In Press, vol. 1673, DOI: 10.1007/978-1-4939-73095_10.

64. Natsume, R., Takeshita, R., Sugiyama, M., Ohnishi, Y., Senda, T., and Horinouchi, S. (2003) Crystallization of CprB, an autoregulator-receptor protein from Streptomyces coelicolor A3(2), Acta Crystallogr., Sect. D: Biol. Crystallogr. 59, 2313-2315.

65. Laemmli, U. K. (1970) Cleavage of structural proteins during the assembly of the head of bacteriophage T4, Nature 227, 680-685.

66. Gottelt, M., Hesketh, A., Bunet, R., Puri, P., and Takano, E. (2012) Characterisation of a natural variant of the gamma-butyrolactone signalling receptor, BMC Res. Notes 5, 379. 
Figure 1

Butyrolactone system

3796 bp

$\left.\overline{\mathrm{scbB}}\rangle^{1000^{\prime}}\left\langle\mathrm{scbR}^{2000^{\prime}} \mathrm{scbA}\right\rangle^{3000^{\prime}} \mathrm{scbC}\right\rangle$

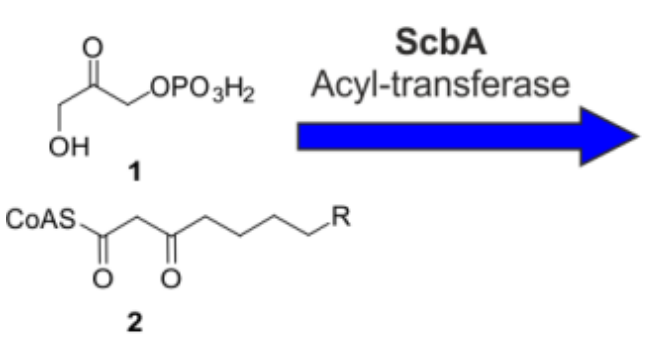

2

ScbB

3-ketoacyl-ACP/CoA

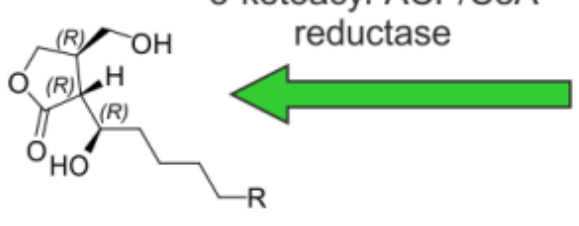

7

SCB1: $\mathrm{R}=$ iso-propyl

SCB2: $R=$ propyl

SCB3: $\mathrm{R}$ = sec-butyl

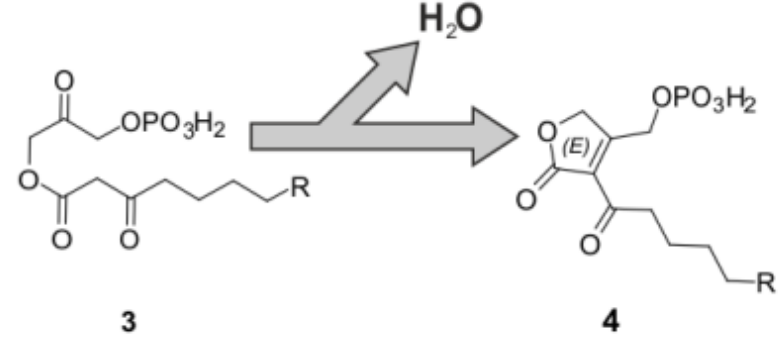

ScbC

butenolide phosphate reductase
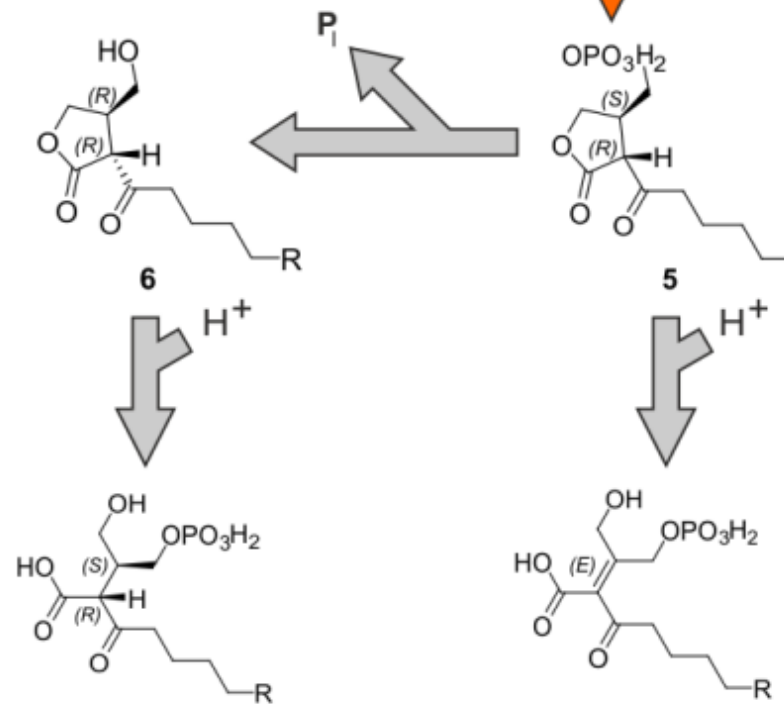

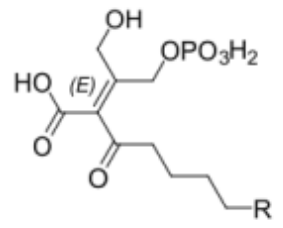

8

Figure 1. Schematic representation of the GBL biosynthesis gene cluster from $S$. coelicolor A3(2) M145 and the possible biosynthetic pathway leading towards production of GBLs: SCB1, SCB2 or SCB3 in S. coelicolor; based on the biosynthetic pathways proposed by Kato et al. (29) for A-factor production in S. griseus and by Shikura et al. (30) for virginiae butanolides in S. virginiae. The biosynthesis of GBLs has been proposed to start with the condensation of DHAP with a $\beta$-ketoacid by $(29,31)$ ScbA in $S$. coelicolor A3(2), leading to product 3 , which putatively undergoes a spontaneous intramolecular Claisen condensation, resulting in butenolide 4. This compound is reduced by a butenolide phosphate reductase, ScbC, yielding 5, which could be hydrolysed, yielding compound $\mathbf{8}$. The phosphate group is lost, resulting in the A-factor-like GBL 6, which can also be hydrolised to render the open lactone $\mathbf{9}$. The final GBLs (7) are obtained after stereo-specific reduction through a 3-ketoacyl-ACP/CoA reductase, ScbB. During transition phase, GBLs accumulate in the environment and bind to the receptor ScbR, resulting in a switch-like transition towards antibiotic production. 
Figure 2

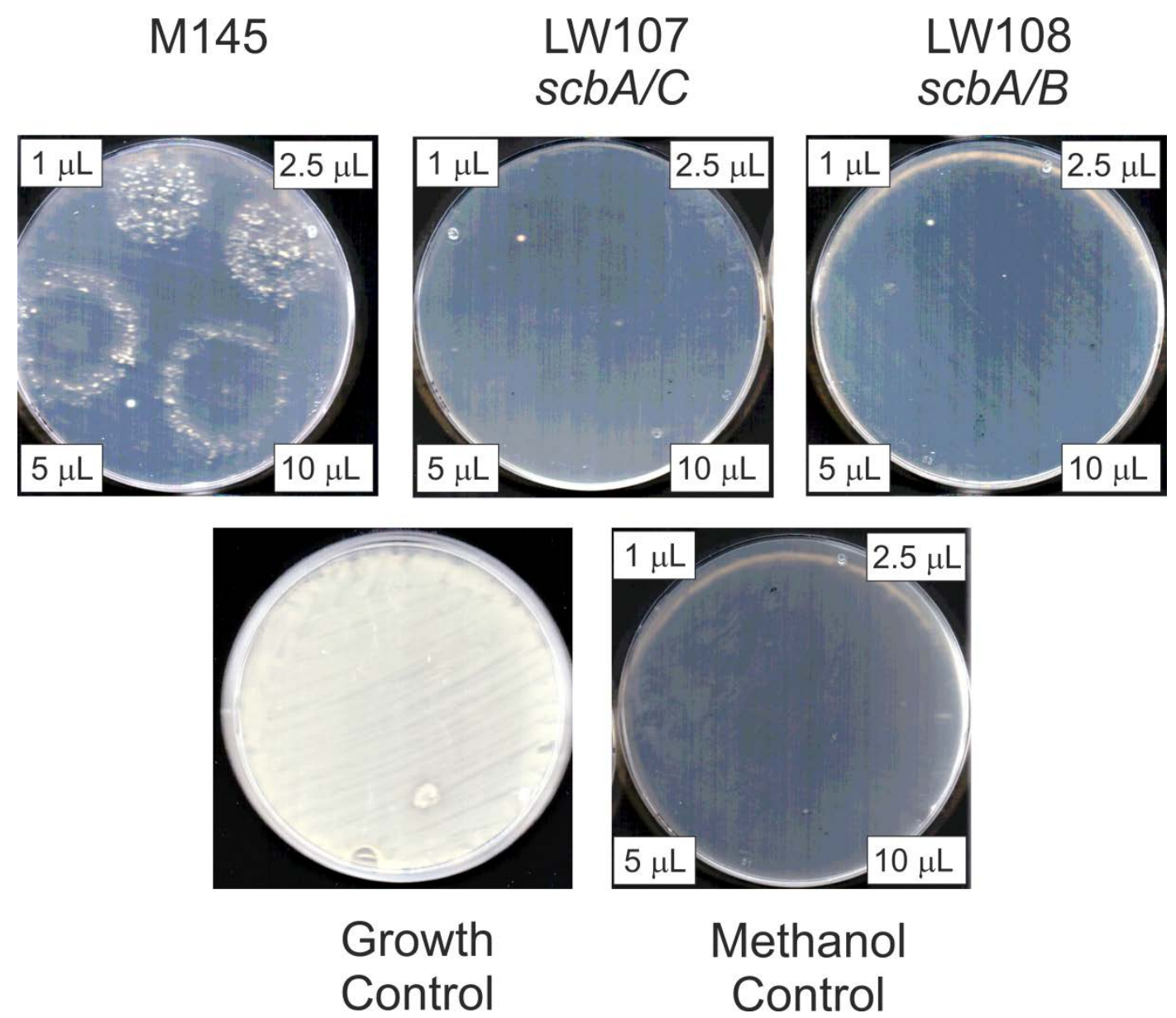

Figure 2. Kanamycin bioassay plates with different concentrations $(1 \mu \mathrm{L}, 2.5 \mu \mathrm{L}, 5 \mu \mathrm{L}$ and $10 \mu \mathrm{L}$ ) of GBL ethyl acetate extracts from the different Streptomyces strains as depicted above the plates. Growth in the presence of kanamycin is detected in all concentrations of $S$. coelicolor M145 extract, whereas no growth is seen for extracts from LW107 (scbA/C) and LW108 $(s c b A / B)$ mutants, suggesting these genes are involved in the production of GBLs. 
Figure 3
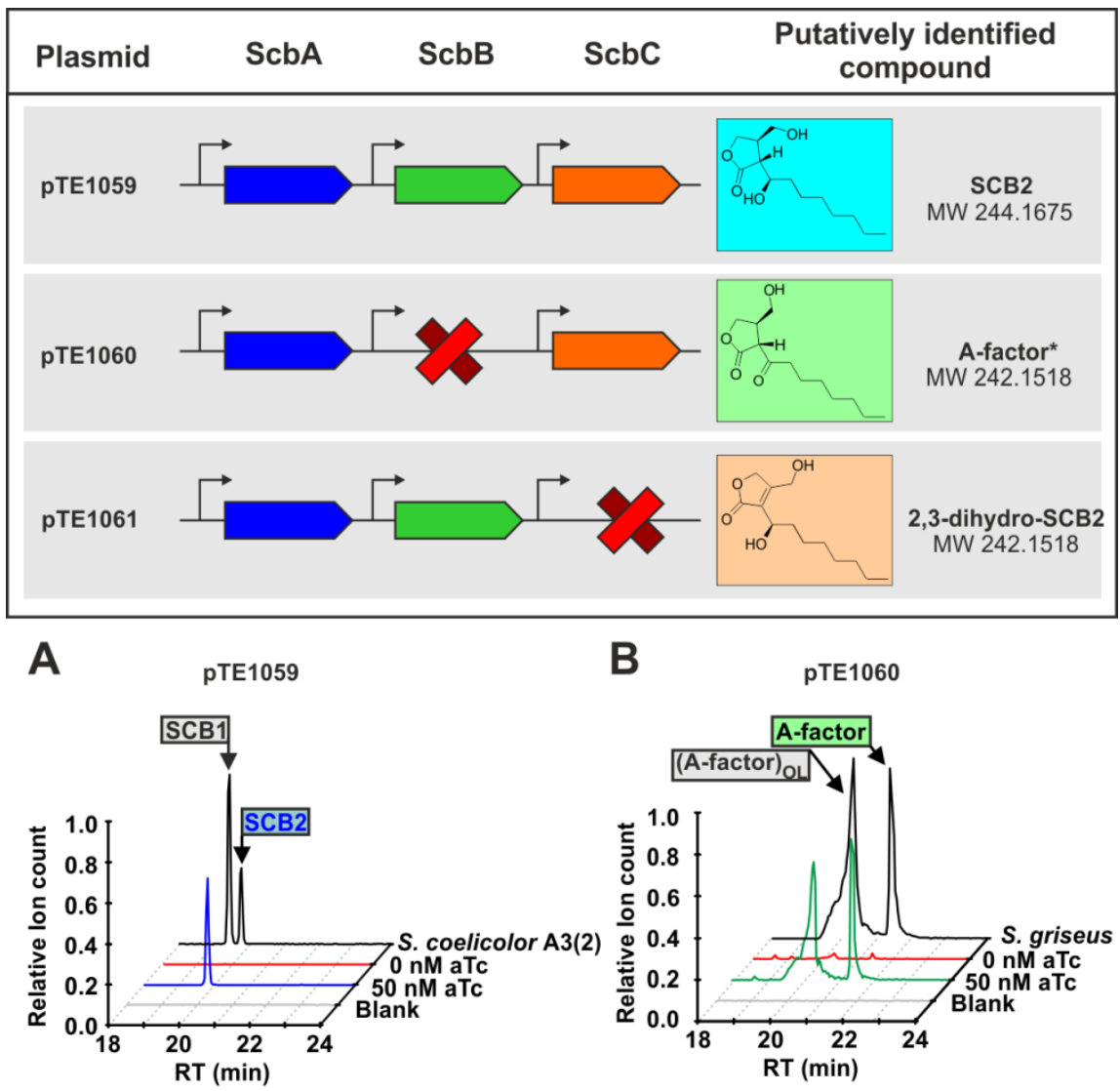

B PTE1060
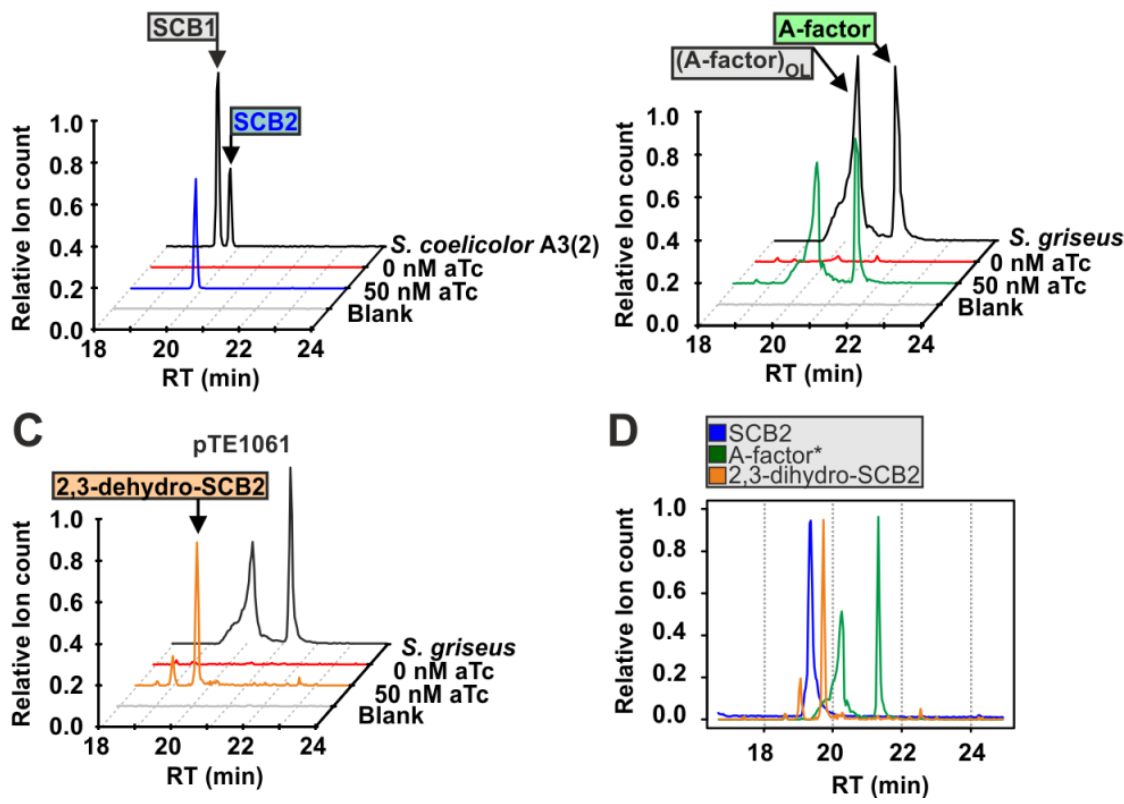

Figure 3. Analysis of intermediate metabolites in GBL biosynthesis through LC-MS. Extracted Ion Chromatograms (EIC) of extracts from E. coli cells expressing pTE1059 $(s c b A / B / C)$, pTE1060 $(s c b A / C)$ or pTE1061 (scbA/B). (A) When expressing the three genes using pTE1059, a EIC peak is detected that elutes at the same retention time as SCB2 from $S$. coelicolor M145 extract. This peak was further shown to be SCB2 by MS/MS analysis (Supplementary Fig. S3). (B) After deleting $s c b B$ in pTE1060, this peak is no longer detectable; instead two peaks are detected at a mass corresponding to A-factor, which elute at the same retention time as the two peaks of A-factor from S. griseus, suggesting that $s c b B$ is responsible for the stereospecific reduction of compound 6. (C) Deletion of $s c b C$ in pTE1061 results in an unidentified detectable peak at a mass corresponding to A-factor, which elutes at a distinctive retention time. The concentration of the anhydrotetracycline (aTc) and the positive control extracts from S. coelicolor or S. griseus is denoted at the side. (D) Overlap of peaks identified in E. coli ethyl acetate extracts showed in panels A - C, highlighting the distinctive retention time between them. 


\section{Figure 4}

A

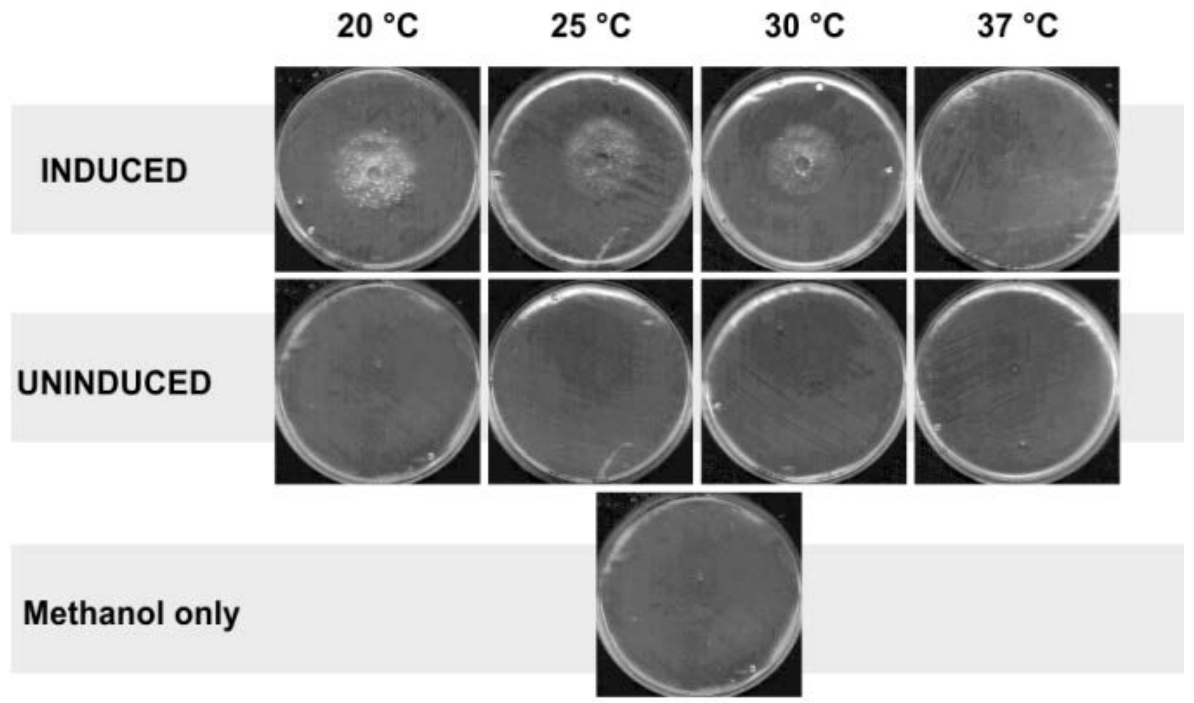

B

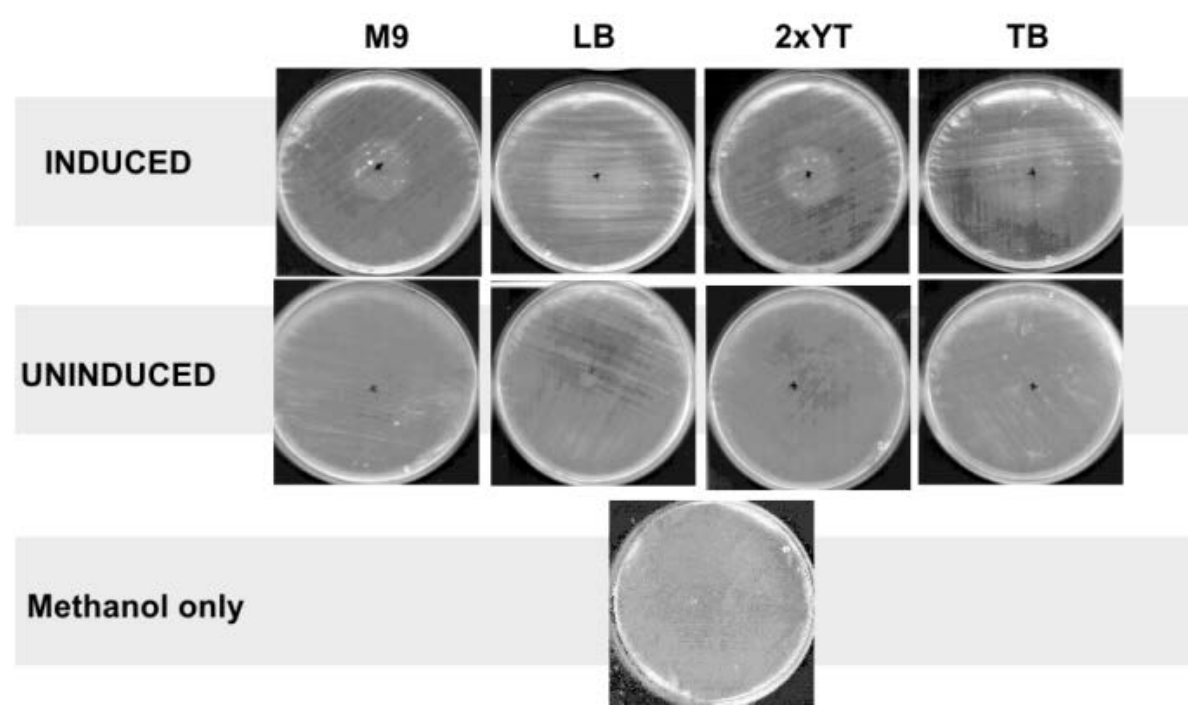

Figure 4. Qualitative production of SCB2 at different temperatures and media. Production of SCB2 in E. coli was assessed under different temperatures from $20^{\circ} \mathrm{C}$ to $37^{\circ} \mathrm{C}$ and different media conditions, minimal to rich media. (A) Kanamycin bioassay with extracts from E. coli producer cells grown at different temperatures. Expression of SCB2 is detected at assayed temperatures from $20-30{ }^{\circ} \mathrm{C}$, but not at $37^{\circ} \mathrm{C}$. (B) Kanamycin bioassay with extracts from $E$. coli harbouring $s c b A / B / C$ (pTE1059) grown under different media. All media allowed production of SCB2. 


\section{Figure 5}

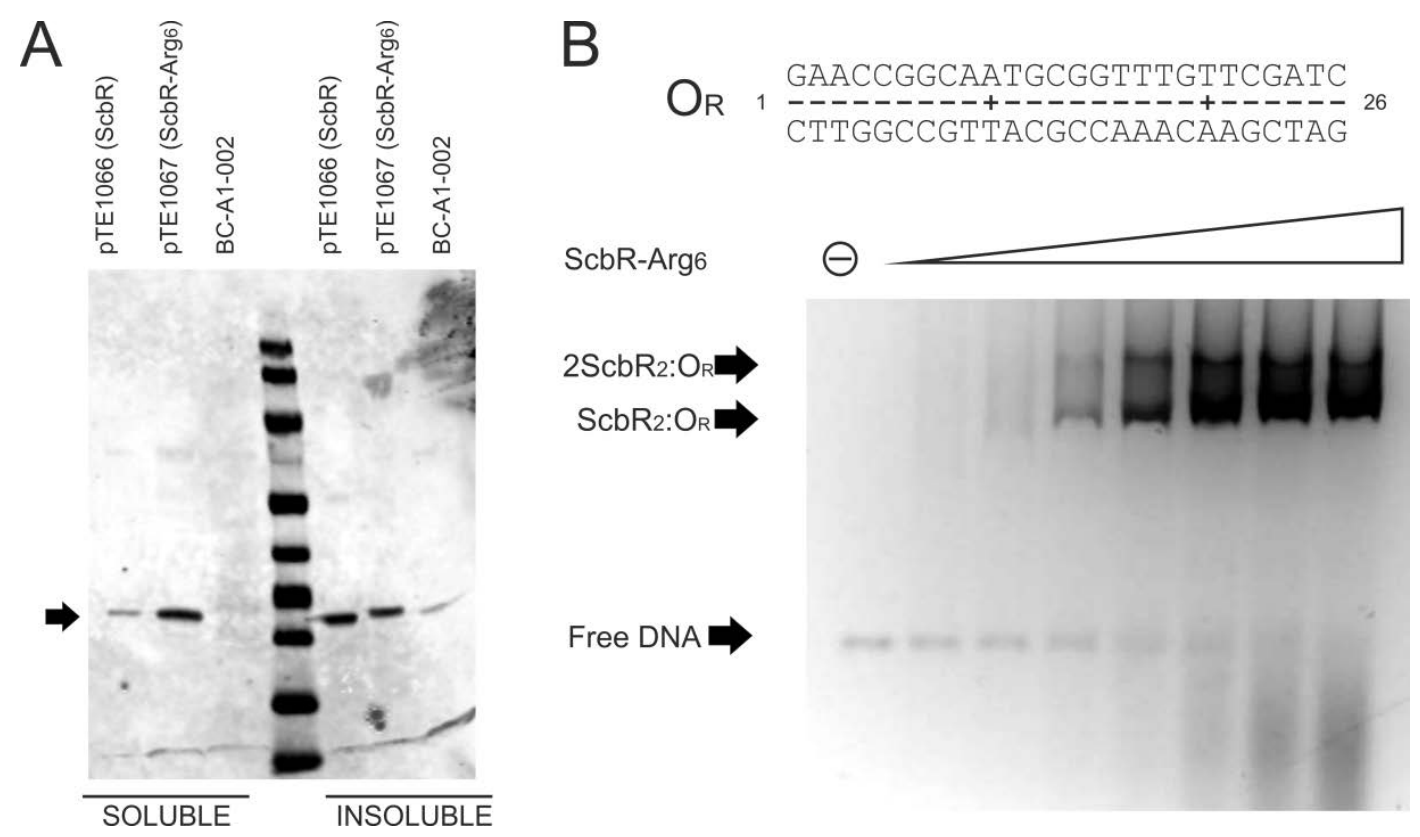

Figure 5. Western Blot and gel retardation analysis of ScbR-Arg . $_{\text {. }}$ (A) Western Blot analysis of ScbR and ScbR-Arg 6 in ScbR + luxp plasmid (pTE1066) and ScbR-Arg 6 + luxp plasmid (pTE1067), respectively, at stationary phase in the soluble and insoluble fractions, and compared to plasmid BC-A1-002, which does not contain ScbR. A faint band corresponding to ScbR (black arrow) can be seen in pTE1066 soluble fraction, which is stronger in pTE1067. Addition of the Arginine tag improved the solubility of ScbR. (B) Gel retardation analysis of ScbR-Arg 6 against a DNA fragment containing the operator sequence $\mathrm{O}_{\mathrm{R}}$ (26). Addition of increasing amounts of ScbR-Arg ${ }_{6}$ results in formation of complex ScbR$\operatorname{Arg}_{6}: \mathrm{O}_{\mathrm{R}}$ and 2 ScbR-Arg $: \mathrm{O}_{\mathrm{R}}$, showing that addition of the $\mathrm{Arg}_{6}$ tag does not affect DNAbinding properties of ScbR. 


\section{Figure 6}
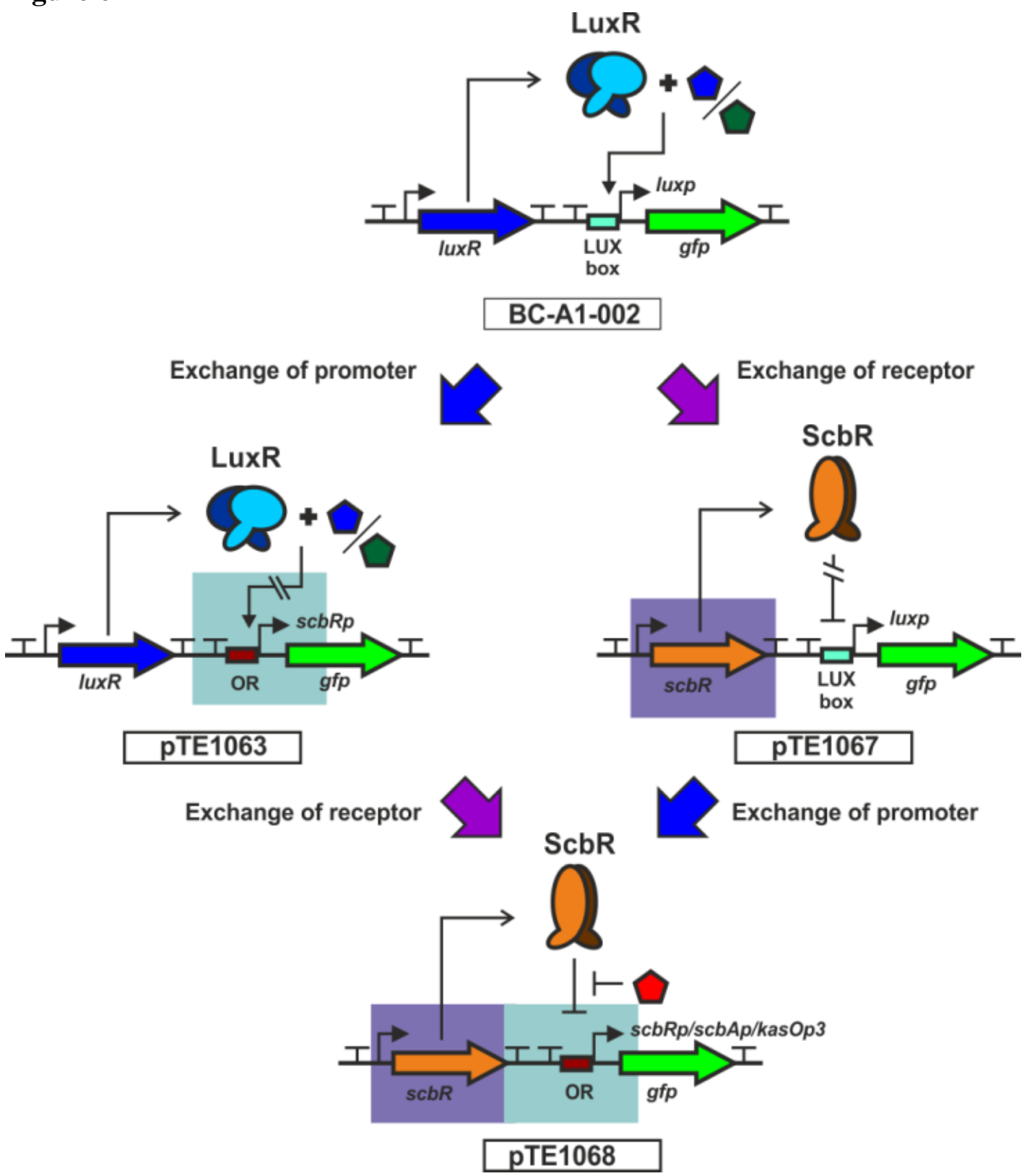

Figure 6. Signal and promoter crosstalk between the AHL and the GBL systems: constructs. Schematic representation of the plasmids built to evaluate signal and promoter crosstalk between the AHL and the GBL systems. In plasmid BC-A1-002 (54), constitutive expression of the luxR results in production of LuxR, which binds to the LUX box when the concentration of AHLs reaches a concentration threshold. There, it induces gfp expression by RNA polymerase recruitment. Exchange of the luxp and the LUX box from BC-A1-002 for $s c b R p$ and ScbR cognate operator site $\left(\mathrm{O}_{\mathrm{R}}\right)$ generated plasmid pTE1063, used to evaluate whether LuxR could interact with ScbR $\mathrm{O}_{\mathrm{R}}$. Parallel construction of pTE1067 was created by replacing luxR for $s c b R-A_{r g}$ and was used to evaluate whether ScbR could interact with the LUX box. Finally, plasmid pTE1058 replaced both the luxp by scbRp and luxR by $s c b R-A r g_{6}$ and should respond only to the addition of SCB2. 
Figure 7

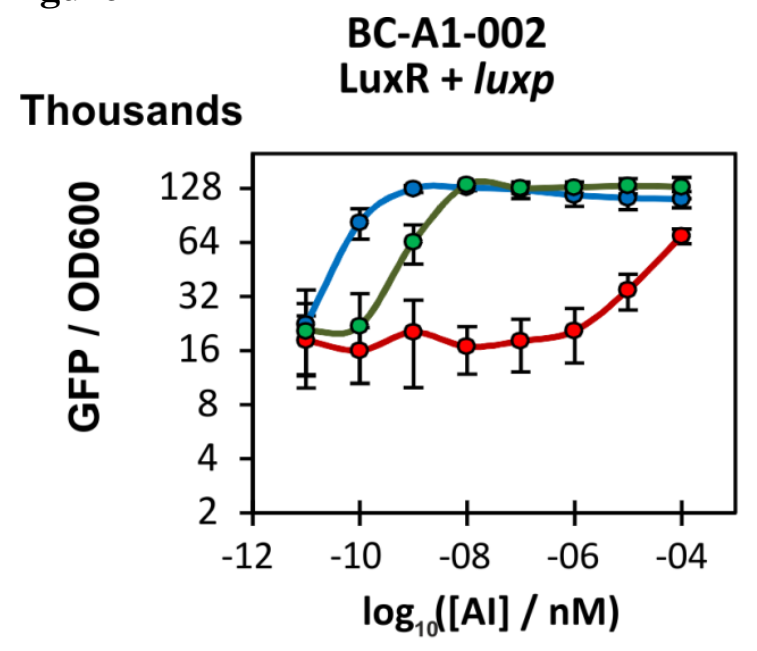

pTE1067

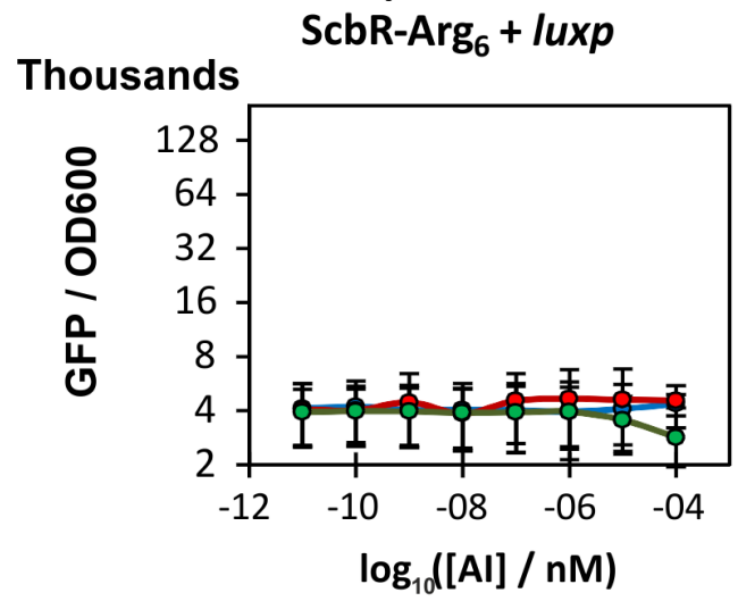

pTE1063

\section{Thousands \\ LuxR + scbRp}

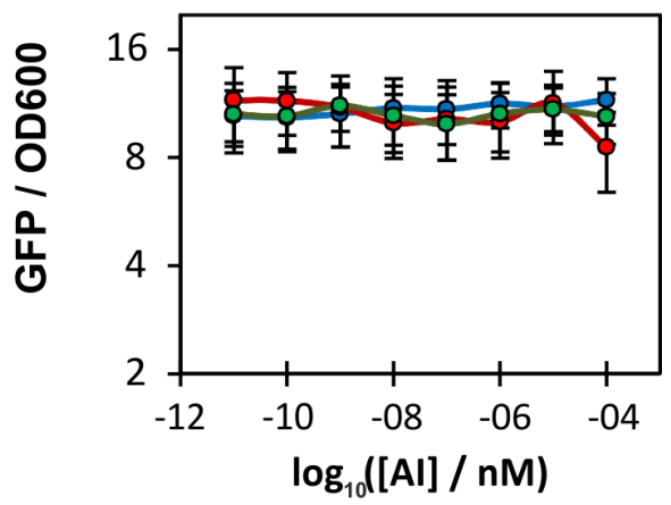

pTE1068

Thousands

$$
\text { ScbR-Arg } 6+s c b R p
$$

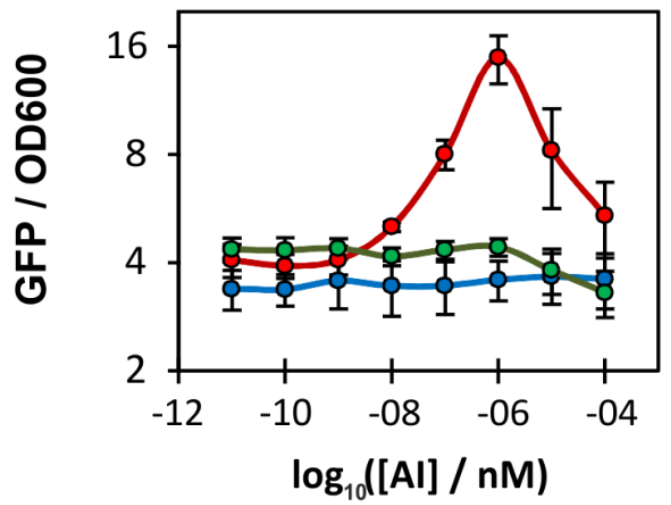

Figure 7. Signal and promoter crosstalk between the AHL and the GBL systems. Normalised GFP/OD 600 output after addition of different concentrations of autoinducer concentrations ([AI]/M), either $3 \mathrm{OC}_{6} \mathrm{HSL}$ (blue line), $3 \mathrm{OC}_{12} \mathrm{HSL}$ (green line) or SCB2 (red line); to strains harbouring plasmids BC-A1-002 (LuxR+luxp), pTE1063 (LuxR+scbRp), pTE1067 (ScbR-Arg 6 +luxp) and pTE1068 (ScbR-Arg $\left.{ }_{6}+s c b R p\right)$ (Fig 6). Measurements were made $\sim 20 \mathrm{~h}$ after induction and growth at $30^{\circ} \mathrm{C}$. Expression of $\mathrm{gfp}$ is at the maximum with concentrations of $10^{-9} \mathrm{M}$ of 3OC6-HSL and $10^{-8} \mathrm{M}$ of 3OC12-HSL, when added to BC-A1002. However, no GFP expression is seen when AHLs are added to the cells with the ScbR$\mathrm{Arg}_{6}+\operatorname{luxp}$ (pTE1067). On the other hand, addition of any signalling molecules results in no change in $g f p$ expression in LuxR+scbRp (pTE1063), where scbRp is always active. GFP expression is induced upon the addition of SCB2 with the ScbR-Arg ${ }_{6}+s c b R p$ (pTE1068). Interestingly, addition of an excess of SCB2 in ScbR-Arg ${ }_{6}+s c b R p$ results in repression of the system. No induction of GFP was observed with addition of AHLs to ScbR-Arg ${ }_{6}+s c b R p$ (pTE1068). 
Figure 8
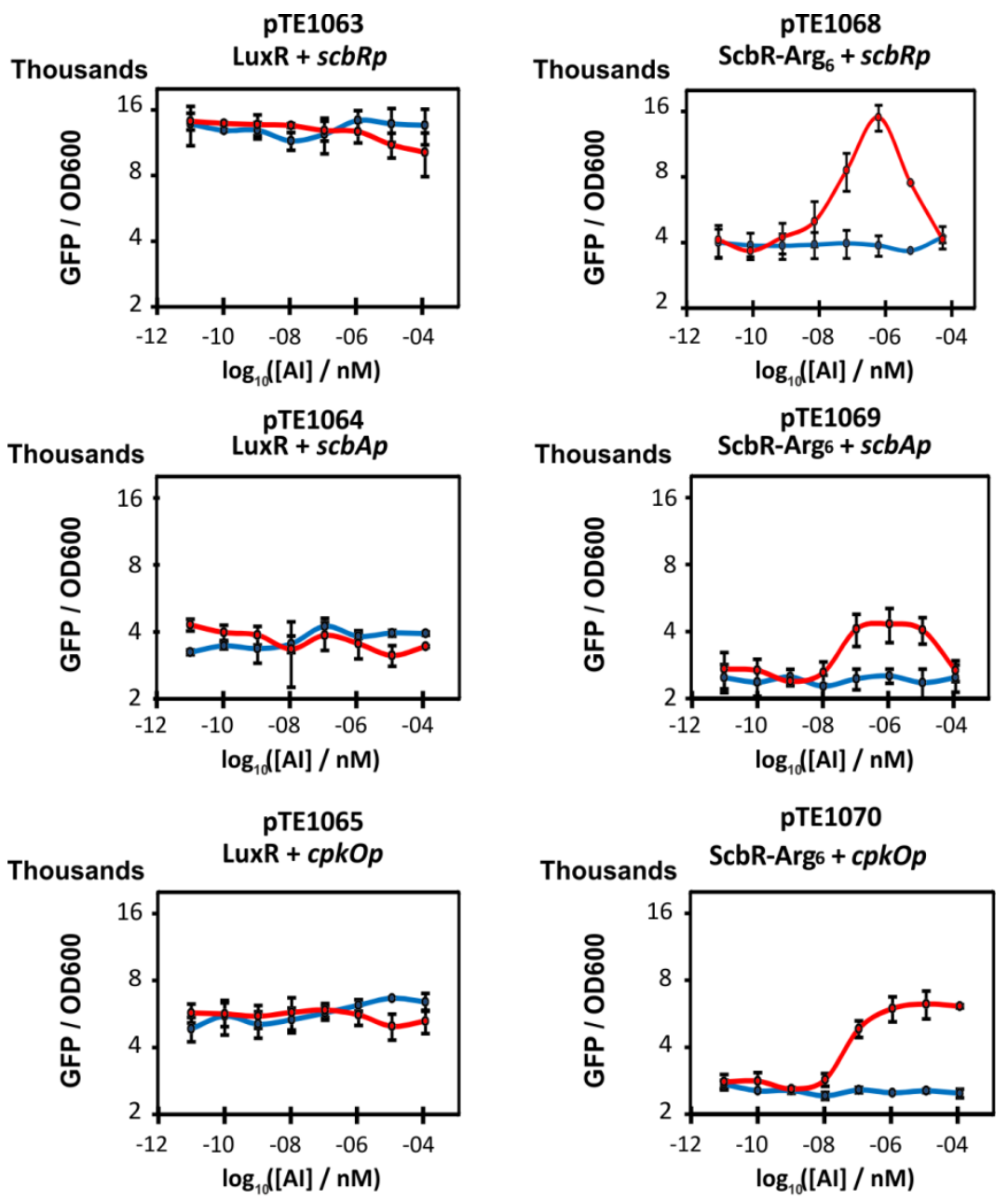

$\multimap$ 30C6-HSL $\multimap-\mathrm{SCB} 2$

Figure 8. Expression of GFP with different ScbR-dependent promoters results in a gradient of output signal. Normalised $\mathrm{GFP} / \mathrm{OD}_{600}$ output after addition of different concentrations of autoinducer ([AI]/M) 3OC ${ }_{6} \mathrm{HSL}$ (blue line) or SCB2 (red line); to strains harbouring pTE1063 (LuxR + scbRp), pTE1064 (LuxR + scbAp), pTE1065 (LuxR + cpkOp), pTE1068 (ScbR-Arg 6 + scbRp), pTE1069 (ScbR-Arg ${ }_{6}+$ scbAp) or pTE1070 (ScbR-Arg 6 + cpkOp). Measurements were made $\sim 20 \mathrm{~h}$ after induction and growth at $30{ }^{\circ} \mathrm{C}$. As seen in Fig 7, plasmids containing LuxR are active at all concentrations of signals, suggesting that LuxR does not interact with any of the ScbR operator sequences to repress the promoters. Exchange of luxR for scbR-Arg6 results in repression of the promoters until around $10^{-9} \mathrm{M}$ of SCB2. Interestingly, both $s c b R p$ and $s c b A p$ are only active in concentrations between $10^{-8}$ to $10^{-4}$ Mof SCB2, respectively. However, cpkOp is active at all concentrations above $10^{-9} \mathrm{M}$, and the activity was not shut down. 


\section{Figure 9}

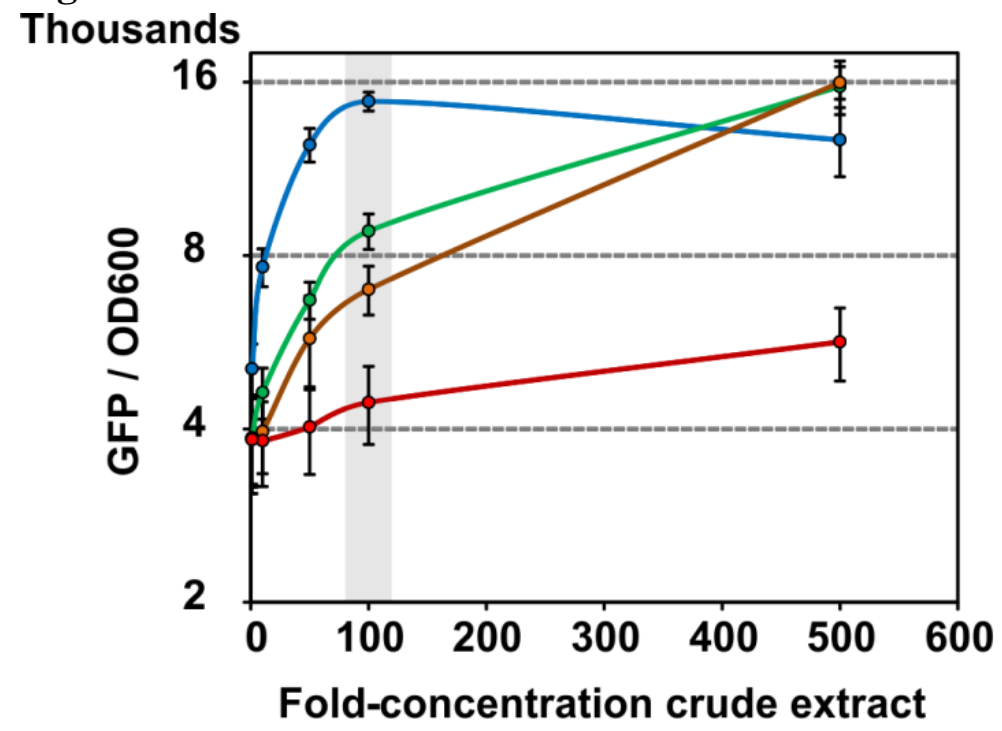

$\multimap 20^{\circ} \mathrm{C}-0-25^{\circ} \mathrm{C}-0-30^{\circ} \mathrm{C}-0-37^{\circ} \mathrm{C}$

Figure 9. Response analysis of plasmid pTE1068 under different extracts obtained from $10 \mathrm{~mL}$ LB culture of $\boldsymbol{E}$. coli producer cells. The results match the previously observed characteristics, where lower temperatures seem to be favourable for SCB2 production (Fig. 3). Interestingly, addition of a 100-fold concentrated ethyl acetate extracts of the liquid culture supernatant to the reporter cells (shaded box) resulted in full activation of $g \mathrm{fp}$ expression at $20^{\circ} \mathrm{C}$ and about half activation of $\mathrm{gfp}$ expression at 25 and $30{ }^{\circ} \mathrm{C}$, suggesting that the system could be used at different temperatures to fine tune gene expression. 